\title{
A Novel Multiperson Game Approach for Linguistic Multicriteria Decision Making Problems
}

\author{
Ching-San Lin, ${ }^{1}$ Chen-Tung Chen, ${ }^{2}$ Farn-Shing Chen, ${ }^{3}$ and Wei-Zhan Hung ${ }^{4}$ \\ ${ }^{1}$ Department of Industrial Education and Technology, National Changhua University of Education, 2 Shi-Da Road, \\ Changhua County, Changhua City 500, Taiwan \\ ${ }^{2}$ Department of Information Management, National United University, 1 Lienda Road, Miaoli County, Miaoli City 36003, Taiwan \\ ${ }^{3}$ Institute of Mechatronoptic Systems and Department of Automation Engineering, Chienkuo Technology University, \\ No. 1 Chiehshou North Road, Changhua City 500, Taiwan \\ ${ }^{4}$ Department of International Business, National Chi Nan University, 1 University Road, Nantou County, Puli City 54561, Taiwan \\ Correspondence should be addressed to Chen-Tung Chen; ctchen@nuu.edu.tw
}

Received 1 September 2013; Revised 2 November 2013; Accepted 24 November 2013; Published 2 February 2014

Academic Editor: Ching-Ter Chang

Copyright (c) 2014 Ching-San Lin et al. This is an open access article distributed under the Creative Commons Attribution License, which permits unrestricted use, distribution, and reproduction in any medium, provided the original work is properly cited.

\begin{abstract}
Game theory is considered as an efficient framework in dealing with decision making problems for two players in the competitive environment. In general, the evaluation values of payoffs matrix are expressed by crisp values in a game model. However, many uncertainties and vagueness should be considered due to the qualitative criteria and the subjective judgment of decision makers in the decision making process. The aim of this study is to develop an effective methodology for solving the payoffs matrix with linguistic variables by multiple decision makers in a game model. Based on the linguistic variables, the decision makers can easily express their opinions with respect to criteria for each alternative. By using the linear programming method, we can find the optimal solution of a game matrix in accordance with the combination of strategies of each player effectively. In addition, the expected performance value (EPV) index is defined in this paper to compare the competition ability of each player based on the optimal probability of each strategy combination. And then, numerical example will be implemented to illustrate the computation process of the proposed model. The conclusion and future research are discussed at the end of this paper.
\end{abstract}

\section{Introduction}

In decision science field, game theory provides an effective way for handing the interactive optimization problems. Game theory started with the publication of "the theory of games and economics behavior" in 1944 by von Neumann and Morgenstern [1]. It is a special tool to analyze the interaction result among players and has been broadly applied in business, financial, politics, education, sports, and so forth [2-5].

There are three basic components in a game such as players, players' strategies, and the performances (payoffs) with respect to the strategies of players. Strategy form and extensive form are two main ways to describe the interaction between players [6]. In strategy form, each player executes his/her strategy simultaneously and the payoff is decided based on the strategy combination of each player. In extensive form, each player executes his/her strategy sequentially and the payoff is the final result based on the decision of each player. In general, the extensive form of a game can be transferred to the strategy form. The different classification types of game included cooperation or noncooperation games, zero-sum or non-zero-sum games, one round or multiround games, two-person or multiperson games.

Recently, the development trend of game theory is to integrate multicriteria decision making (MCDM) method to deal with the decision-making problems in real situations. There are some literatures that have been proposed by combining multicriteria decision method (MCDM) with game theory for coping with the decision making problems.

Campos [7] proposed a two-person zero sum fuzzy matrix game and applied fuzzy linear programming to calculate the mixed strategy probability of each player. Sakawa and 
Nishizaki [8] applied the max-min concept to integrate fuzzy goals and fuzzy payoffs in a two-person zero sum game. Song and Kandel [6] applied fuzzy set to formulate the goals of players and the strategy probability of their competitors. The mixed strategy probability is calculated based on considering their goals and the probability of each strategy of competitors simultaneously. The drawback of Song and Kandel's model is that it is difficult to compute the game matrix with multiple persons. Wang [9] built a fuzzy linear programming model to deal with $N$-person multiattribute noncooperative game. Liao [10] applied fuzzy linear goal programming to solve a two-person zero sum game for analyzing the wireless market in Taiwan. Angelou and Economides [11] integrated analytic hierarchy process, game theory, and real options to analyze the business alternatives of information and communication technology (ICT). Reneke [12] used the vector function to evaluate long term investment alternatives for predicting oil prices and environmental degradation under the conditions of risk and uncertainty. Madani and Lund [13] used Monte-Carlo game theory (MCGT) technology to handle the uncertainty problem with the deterministic strategic games. Monroy and Fernández [14] extended the Shapley-Shubik index from conventional simple games to deal with the multi-criteria game problem. Barough et al. [15] used the traditional game approach to deal with two types of project construction conflict problem. Li and Hong [16] developed an effective methodology for handling the constrained matrix game with fuzzy payoffs. Monroy and Fernández [17] used voting systems to handle multi-criteria simple games in social-choice situation. The stable set and the core are the solution concept in the multi-criteria simple games. Different kinds of aggregation operators such as union, intersection, marginalization, and composition can be applied in their method. Lozan and Ungureanu [18] used graphs intersection method of the best response mappings to deal with the two-criterion games. Pusillo and Stef Tijs [19] used the improvement sets for developing the equilibrium condition for noncooperative multi-criteria games. Kawamura et al. [20] extended neutrally and evolutionarily stable strategies from single-criterion game to multi-criteria games. In entropy environment, Roy and Das [21] handled the multi-criteria bimatrix goal game problem by determining Ggoal security strategies. They applied the real coded genetic algorithm to acquire the bounds of the objectives of the proposed game. The fuzzy programming technique is used to solve the formulated model.

Although many literatures have been proposed by applying game theory to make a decision, few of them can integrate MCDM and game theory to handle the multiperson multicriteria game in a fuzzy environment. In real environment, each player will compete with other players. A good player not only should consider his/her strategy for approaching his/her goal but also need to forecast the behaviors of competitors. There is usually more than one influenced factor that should be considered by each player in a game model. In addition, the uncertainty and fuzziness will happen in the real competitive environment because it is not easy to collect the decision information completely and the decision time is limited for making a decision. A good model must provide

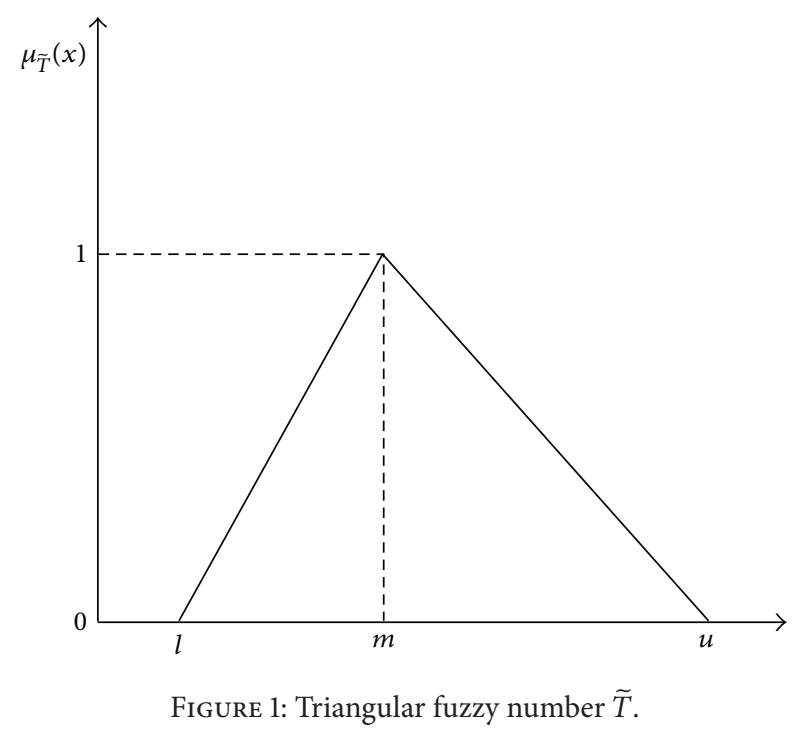

a mechanism such as linguistic value or fuzzy number for experts to express their opinions flexibly.

However, the original game model usually considers one dimension or criterion to make a decision and the crisp values are used to evaluate the performance with respect to the dimension by single decision maker. In order to overcome the drawbacks of original game model, the main purpose of this study is to develop a new decision making method, linguistic multiperson multi-criteria game (LMPMCG) model, for dealing with the game problems under multiperson and multi-criteria environment. According to the linguistic variable, the decision makers can easily express their opinions with respect to each criterion for each alternative (strategy combination). By using the linear programming method, we can find the optimal solution of a game matrix effectively.

The reminder of this study is organized as follows. In Section 2, the definitions of linguistic variables and fuzzy numbers will be introduced. After that, the linguistic multiperson multi-criteria game model is presented at Section 3. And then, an example is implemented for the new mobile phone development project selection problem. Finally, conclusion and future research are discussed at the end of this paper.

\section{Fuzzy Set and Linguistic Variable}

Fuzzy set theory is first introduced by Zadeh in 1965 [22]. Fuzzy set theory is a very feasible method to handle the imprecise and uncertain information in a real world [23, 24]. Especially, it is more suitable for experts to express their subjective judgments and qualitative assessments in the decision making processes [25-27].

A positive triangular fuzzy number (PTFN) $\widetilde{T}$ can be defined as $\widetilde{T}=(l, m, u)$, where $l \leq m \leq u$ and $l>0$ (shown in Figure 1). The membership function $\mu_{\widetilde{T}}(x)$ of positive triangular fuzzy number (PTFN) $\widetilde{T}$ is defined as $[28,29]$ 
TABLE 1: Linguistic variables.

\begin{tabular}{lclrr}
\hline \multicolumn{1}{c}{ Performance } & & & Weight & \\
Linguistic variables & Abbr. & Linguistic variables & Abbr. & $(0.000,0.000,0.125)$ \\
\hline Extremely poor & EP & Extremely low & EL & $(0.000,0.125,0.250)$ \\
Very poor & VP & Very low & VL & $(0.125,0.250,0.375)$ \\
Poor & $\mathrm{P}$ & Low & $\mathrm{L}$ & $(0.250,0.375,0.500)$ \\
Medium poor & $\mathrm{MP}$ & Medium low & $\mathrm{ML}$ & $(0.375,0.500,0.625)$ \\
Fair & $\mathrm{F}$ & Fair & $\mathrm{F}$ & $(0.500,0.625,0.750)$ \\
Medium good & $\mathrm{MG}$ & Medium high & $\mathrm{MH}$ & $(0.625,0.750,0.875)$ \\
Good & $\mathrm{G}$ & High & $\mathrm{HH}$ & $(0.750,0.875,1.000)$ \\
Very good & $\mathrm{VG}$ & Very high & $\mathrm{EH}$ & $(0.875,1.000,1.000)$ \\
Extremely good & $\mathrm{EG}$ & Extremely high & &
\end{tabular}

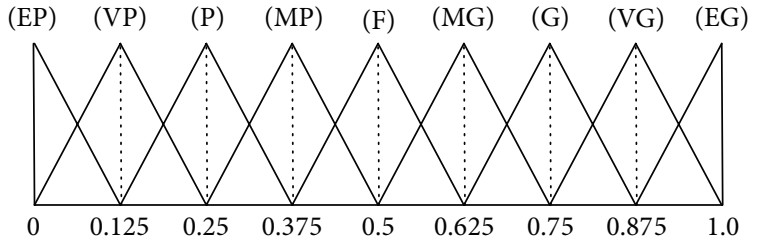

FIgURE 2: Membership functions of linguistic variables.

$$
\mu_{\widetilde{T}}(x)= \begin{cases}\frac{x-l}{m-l}, & l<x<m \\ \frac{u-x}{u-m}, & m<x<u \\ 0, & \text { otherwise. }\end{cases}
$$

A linguistic variable is a variable whose values are expressed in linguistic terms, in other words, variable whose values are not numbers but words or sentences in a nature or artificial language [30-32]. For example, "weight" is a linguistic variable whose values can be very low, low, medium, high, very high, and so forth. These linguistic values can also be represented by fuzzy numbers. There are two advantages for using triangular fuzzy number to express linguistic variable [33, 34]. First, it is a rational and simple method to use triangular fuzzy number to express the opinions of experts. Second, it is easy to make the arithmetic operations between fuzzy numbers when using triangular fuzzy numbers to express the linguistic variables. It is suitable to represent the degree of subjective judgment in qualitative aspect than crisp value. Some linguistic variables and their membership functions can be illustrated as Table 1 and Figure 2.

Let $\widetilde{T}_{1}=\left(L_{1}, M_{1}, U_{1}\right)$ and $\widetilde{T}_{2}=\left(L_{2}, M_{2}, U_{2}\right)$ be two PTFNs. The additive operation of PTFNs can be calculated as $[28,33]$

$$
\widetilde{T}_{1} \oplus \widetilde{T}_{2}=\left(L_{1}+L_{2}, M_{1}+M_{2}, U_{1}+U_{2}\right) .
$$

Many ranking methods have been developed to transform fuzzy number into crisp value. Lee and Li [35] presented the generalized mean value method to rank fuzzy numbers. It is very easy to compare fuzzy numbers by this method. This method has been applied in decision science, personnel selection, weapon selection and supplier selection fields, and so forth [36-39]. Suppose that $\widetilde{T}=(l, m, u)$ is a PTFN, the defuzzied value is easily computed as $[35,36]$

$$
G(\widetilde{T})=\frac{(l+m+u)}{3}
$$

If $\left(\widetilde{T}_{1}\right)>G\left(\widetilde{T}_{2}\right)$, then $\widetilde{T}_{1}>\widetilde{T}_{2}$.

\section{Linguistic Multiperson Multicriteria Game (LMPMCG) Model}

In real environment, each player must compete with other players to determine the actions. A good player not only must consider the own strategies for approaching the goals but also need to forecast the behaviors of their competitors to select the best reaction. Under this situation, many influenced criteria should be considered by each player to make a strategy decision in a game system. Because the different strategies of players will influence the performance of each other, we need to consider the strategies of each player based on a strategy combination. A strategy combination means combination of strategies of players in a specific situation. From this viewpoint, a new game model with linguistic variables for the multiperson multi-criteria problem is proposed in this study.

3.1. Basic Notation of LMPMCG Model. Generally speaking, the contents of linguistic multiperson multi-criteria game (LMPMCG) model can be illustrated as follows.

(1) A set of players is called $P=\left\{P^{1}, P^{2}, \ldots, P^{v}\right\}$, where $v$ represents the number of players.

(2) A set of strategies of each player is called $S=$ $\left\{S^{1}, S^{2}, \ldots, S^{\nu}\right\}$, where $S^{1}=\left\{s_{1}^{1}, s_{2}^{1}, \ldots, s_{m_{1}}^{1}\right\}, S^{2}=$ $\left\{s_{1}^{2}, s_{2}^{2}, \ldots, s_{m_{2}}^{2}\right\}, \ldots, S_{v}=\left\{s_{1}^{v}, s_{2}^{v}, \ldots, s_{m_{v}}^{v}\right\}$. The $m_{1}$, $m_{2}, \ldots, m_{v}$ is the number of strategies for player 1 , player $2, \ldots$, and player $v$. The $s_{\pi}^{\delta}$ represents the $\pi$ th strategy of player $\delta$.

(3) A set of strategies combination is $\mathrm{SC}=$ $\left[s_{i}^{1}, s_{j}^{2}, \ldots, s_{k}^{v}\right]_{m_{1} * m_{2} * \cdots * m_{v}}$. A strategy combination means a combination of the strategy of each player in a specific situation. 
(4) A set of criteria with respect to each strategy combination of each player is $C=\left\{C^{1}, C^{2}, \ldots, C^{\nu}\right\}$, where $C^{1}=\left\{c_{1}^{1}, c_{2}^{1}, \ldots, c_{n_{1}}^{1}\right\}, C^{2}=\left\{c_{1}^{2}, c_{2}^{2}, \ldots, c_{n_{2}}^{2}\right\}, \ldots, C_{v}=$ $\left\{c_{1}^{v}, c_{2}^{v}, \ldots, c_{n_{v}}^{v}\right\}$. The $n_{1}, n_{2}, \ldots, n_{v}$ is the number of the criteria for player 1 , player $2, \ldots$, and player $v$. The $c_{\pi}^{\delta}$ represents the $\pi$ th strategy criteria of player $\delta$.

(5) A set of strategies combination evaluation matrix of each player is $E=\left\{E^{1}, E^{2}, \ldots, E^{v}\right\}$, where $E^{i}=$ $\left[\widetilde{x}_{\left(s_{i}^{1}, s_{j}^{2}, \ldots, s_{k}^{v}\right), c_{\pi}^{i}}^{i}\right]_{\left(m_{1} * m_{2} * \cdots * m_{v}\right) * n_{i}}, i=1,2, \ldots, v$, and $\tilde{x}_{\left(s_{i}^{1}, s_{j}^{2}, \ldots, s_{k}^{v}\right), c_{\pi}^{i}}^{i}$ represents the strategy performance of player $i$ with respect to criterion $c_{\pi}^{i}$ under strategy combination $\left(s_{i}^{1}, s_{j}^{2}, \ldots, s_{k}^{v}\right)$.

(6) A set of decision makers or experts is $D=$ $\left\{D_{1}, D_{2}, \ldots, D_{r}\right\}$, where $r$ represents the number of decision makers.

3.2. Aggregation Process. In a game model, decision makers should express their opinions for the performance of each strategy combination with respect to each criterion based on the standpoint of each player. In general, the linguistic variables are suitable for decision makers used to express their subjective judgment. For a strategy combination $\left(s_{i}^{1}, s_{j}^{2}, \ldots, s_{\theta}^{\delta}, \ldots, s_{k}^{v}\right)$, the performance evaluation of decision maker $d$ with respect to criterion $c_{\pi}^{\delta}$ can be represented as a linguistic variable $\tilde{x}_{\left(s_{i}^{1}, s_{j}^{2}, \ldots, s_{\theta}^{\delta}, \ldots, s_{k}^{v}\right), c_{\pi}^{\delta}}^{d}$. This linguistic variable can be formulated as a PTFN $=(a, b, c)$ where

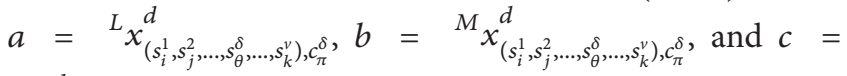
$U_{\left(s_{i}^{1}, s_{j}^{2}, \ldots, s_{\theta}^{\delta}, \ldots, s_{k}^{v}\right), c_{\pi}^{\delta}}^{d}($ refer to Table 1).

For a strategy combination $\left(s_{i}^{1}, s_{j}^{2}, \ldots, s_{\theta}^{\delta}, \ldots, s_{k}^{v}\right)$, the aggregated performance evaluation of decision makers with respect to criterion $c_{\pi}^{\delta}$ can be computed as

$$
\begin{gathered}
\tilde{x}_{\left(s_{i}^{1}, s_{j}^{2}, \ldots, s_{\theta}^{\delta}, \ldots, s_{k}^{v}\right), c_{\pi}^{\delta}} \\
=\frac{1}{r} *\left(\tilde{x}_{\left(s_{i}^{1}, s_{j}^{2}, \ldots, s_{\theta}^{\delta}, \ldots, s_{k}^{v}\right), c_{\pi}^{\delta}}^{1} \oplus \tilde{x}_{\left(s_{i}^{1}, s_{j}^{2}, \ldots, s_{\theta}^{\delta}, \ldots, s_{k}^{v}\right), c_{\pi}^{\delta}}^{2}\right. \\
\left.\oplus \cdots \oplus \tilde{x}_{\left(s_{i}^{1}, s_{j}^{2}, \ldots, s_{\theta}^{\delta}, \ldots, s_{k}^{v}\right), c_{\pi}^{\delta}}^{r}\right)
\end{gathered}
$$

where $\widetilde{x}_{\left(s_{i}^{1}, s_{j}^{2}, \ldots, s_{\theta}^{\delta}, \ldots, s_{k}^{v}\right), c_{\pi}^{\delta}}$ represents the aggregated performance with respect to criterion $c_{\pi}^{\delta}$ under a strategy combination $\left(s_{i}^{1}, s_{j}^{2}, \ldots, s_{\theta}^{\delta}, \ldots, s_{k}^{v}\right)$ based on the opinions of decision makers.

The aggregated performance evaluation of decision makers with respect to criterion $c_{\pi}^{\delta}$ under the strategy combination $\left(s_{i}^{1}, s_{j}^{2}, \ldots, s_{\theta}^{\delta}, \ldots, s_{k}^{v}\right)$ can be defuzzied as

$$
x_{\left(s_{i}^{1}, s_{j}^{2}, \ldots, s_{\theta}^{\delta}, \ldots, s_{k}^{v}\right), c_{\pi}^{\delta}}=G\left(\tilde{x}_{\left(s_{i}^{1}, s_{j}^{2}, \ldots, s_{\theta}^{\delta}, \ldots, s_{k}^{v}\right), c_{\pi}^{\delta}}\right),
$$

$$
\begin{aligned}
& \text { where } G\left(\widetilde{x}_{\left.\left(s_{i}^{1}, s_{j}^{2}, \ldots, s_{\theta}^{\delta}, \ldots, s_{k}^{v}\right), c_{\pi}^{\delta}\right)}=\left({ }^{L} x_{\left(s_{i}^{1}, s_{j}^{2}, \ldots, s_{\theta}^{\delta}, \ldots, s_{k}^{v}\right), c_{\pi}^{\delta}}+\right.\right. \\
& \left.M_{\left(s_{i}^{1}, s_{j}^{2}, \ldots, s_{\theta}^{\delta}, \ldots, s_{k}^{v}\right), c_{\pi}^{\delta}}+{ }^{U} x_{\left(s_{i}^{1}, s_{j}^{2}, \ldots, s_{\theta}^{\delta}, \ldots, s_{k}^{v}\right), c_{\pi}^{\delta}}\right) / 3 .
\end{aligned}
$$

The weight of criterion $c_{\pi}^{\delta}$ of decision maker $d$ can be represented as a linguistic variable $\widetilde{w}_{c_{\pi}^{\delta}}^{d}$. It can be formulated as a PTFN $=(a, b, c)$ where $a={ }^{L} w_{c_{\pi}^{\delta}}^{d}, b={ }^{M} w_{c_{\pi}^{\delta}}^{d}$, and $c={ }^{U}{ }_{c_{\pi}^{\delta}}^{d}$ (refer to Table 1 ).

The aggregated weight of criterion $c_{\pi}^{\delta}$ can be computed as

$$
\widetilde{w}_{c_{\pi}^{\delta}}=\frac{1}{r} *\left(\widetilde{w}_{c_{\pi}^{\delta}}^{1} \oplus \widetilde{w}_{c_{\pi}^{\delta}}^{2} \oplus \cdots \oplus \widetilde{w}_{c_{\pi}^{\delta}}^{r}\right)
$$

where $\widetilde{w}_{c_{\pi}^{\delta}}$ represents the aggregated weight with respect to criterion $c_{\pi}^{\delta}$ based on the opinions of decision makers. as

The aggregated weight of criterion $c_{\pi}^{\delta}$ can be defuzzified

$$
w_{c_{\pi}^{\delta}}=G\left(\widetilde{w}_{c_{\pi}^{\delta}}\right)
$$

where $G\left(\widetilde{w}_{c_{\pi}^{\delta}}\right)=\left({ }^{L} w_{c_{\pi}^{\delta}}+{ }^{M} w_{c_{\pi}^{\delta}}+{ }^{U} w_{c_{\pi}^{\delta}}\right) / 3$.

3.3. Decision Process. For the strategy combination $\left(s_{i}^{1}, s_{j}^{2}\right.$, $\left.\ldots, z s_{\theta}^{\delta}, \ldots, s_{k}^{v}\right)$, the weighted performance of strategy $s_{\theta}^{\delta}$ for player $\delta$ with respect to criterion $c_{\pi}^{\delta}\left(\pi=1,2, \ldots, n_{\delta}\right)$ can be calculated as

$$
P_{\left(s_{i}^{1}, s_{j}^{2}, \ldots, s_{\theta}^{\delta}, \ldots, s_{k}^{v}\right), c_{\pi}^{\delta}}=x_{\left(s_{i}^{1}, s_{j}^{2}, \ldots, s_{\theta}^{\delta}, \ldots, s_{k}^{v}\right), c_{\pi}^{\delta}} *\left(\frac{w_{c_{\pi}^{\delta}}}{\left(\sum_{i=1}^{n_{\delta}} w_{c_{i}^{\delta}}\right)}\right),
$$

where $p_{\left(s_{i}^{1}, s_{j}^{2}, \ldots, s_{\theta}^{\delta}, \ldots, s_{k}^{v}\right), c_{\pi}^{\delta}}$ represents the weighted performance of strategy $s_{\theta}^{\delta}$ for player $\delta$ with respect to criterion $c_{\pi}^{\delta}$ under strategy combination $\left(s_{i}^{1}, s_{j}^{2}, \ldots, s_{\theta}^{\delta}, \ldots, s_{k}^{v}\right)$ and $\left(w_{c_{\pi}^{\delta}} /\right.$ $\left.\left(\sum_{i=1}^{n_{\delta}} w_{c_{i}^{\delta}}\right)\right)$ represents the normalized weight of criterion $c_{\pi}^{\delta}$.

For the strategy combination $\left(s_{i}^{1}, s_{j}^{2}, \ldots, s_{\theta}^{\delta}, \ldots, s_{k}^{v}\right)$, the integrated performance of player $\delta$ with respect to all criteria can be calculated as

$$
\Psi_{\left(s_{i}^{1}, s_{j}^{2}, \ldots, s_{\theta}^{\delta}, \ldots, s_{k}^{v}\right)}=\sum_{i=1}^{n_{\delta}} P_{\left(s_{i}^{1}, s_{j}^{2}, \ldots, s_{\theta}^{\delta}, \ldots, s_{k}^{v}\right), c_{i}^{\delta},}
$$

where $\Psi_{\left(s_{i}^{1}, s_{j}^{2}, \ldots, s_{\theta}^{\delta}, \ldots, s_{k}^{v}\right)}$ represents the integrated performance of player $\delta$ with respect to all criteria under the strategy combination $\left(s_{i}^{1}, s_{j}^{2}, \ldots, s_{\theta}^{\delta}, \ldots, s_{k}^{v}\right)$. It means the overall performance for player $\delta$ when player 1 chooses strategy $s_{i}^{1}$, player 2 chooses strategy $s_{j}^{2}, \ldots$, player $\delta$ chooses strategy $s_{\theta}^{\delta}, \ldots$, and player $v$ chooses strategy $s_{k}^{v}$.

The optimal probability of each strategy for player $\delta$ can be computed by considering all strategy combinations of all players. Under this situation, player $\delta$ will maximize the expected performance by calculating the optimal probability of each strategy. Therefore, the problem of optimal probability 
TABLE 2: The strategies and evaluation criteria of each enterprise.

\begin{tabular}{|c|c|c|}
\hline & Strategy & Criteria \\
\hline \multirow{5}{*}{$P^{1}$} & & $c_{1}^{1}$ : Mobile margin profit \\
\hline & $s_{1}:$ Develop new high level mobile phone, & $c_{2}^{1}:$ Market share rate \\
\hline & $s_{2}^{1}$ : Develop new middle level mobile phone & \\
\hline & $s_{2}^{1}:$ Develop new low level mobile phone & \\
\hline & & $c_{4}^{1}:$ Research time \\
\hline \multirow{3}{*}{$P^{2}$} & $s_{1}^{2}$ : Develop new high level mobile phone & $c_{1}^{2}:$ Market share rate \\
\hline & $s_{2}^{2}:$ Develop new low level mobile phone & $c_{2}^{2}:$ Enterprise's total cost \\
\hline & $s_{3}^{2}$ : Promote and manufacture old mobile phone & $c_{3}^{2}$ : Enterprise's net profit \\
\hline \multirow{4}{*}{$P^{3}$} & & $c_{1}^{3}$ : Enterprise's net profit \\
\hline & $s_{1}^{3}$ : Develop new middle level mobile phone & $c_{2}^{3}:$ Mobile margin profit \\
\hline & $s_{2}^{3}:$ Develop new low level mobile phone & $c_{3}^{3}$ : Research cost \\
\hline & & $c_{4}^{3}:$ Research time \\
\hline
\end{tabular}

TABLE 3: The linguistic performance of enterprise $P^{1}$ with respect to criteria for each strategy combination.

\begin{tabular}{|c|c|c|c|c|c|c|c|c|c|c|c|c|}
\hline \multirow{2}{*}{$\begin{array}{l}\text { Strategy } \\
\text { combination }\end{array}$} & \multicolumn{3}{|c|}{$c_{1}^{1}$} & \multicolumn{3}{|c|}{$c_{2}^{1}$} & \multicolumn{3}{|c|}{$c_{3}^{1}$} & \multicolumn{3}{|c|}{$c_{4}^{1}$} \\
\hline & $D_{1}$ & $\mathrm{D}_{2}$ & $D_{3}$ & $D_{1}$ & $D_{2}$ & $D_{3}$ & $D_{1}$ & $D_{2}$ & $D_{3}$ & $D_{1}$ & $\mathrm{D}_{2}$ & $D_{3}$ \\
\hline$s_{1}^{1}, s_{1}^{2}, s_{1}^{3}$ & $\mathrm{G}$ & MG & $\mathrm{VP}$ & $G$ & $\mathrm{~F}$ & MP & G & G & $\mathrm{F}$ & $\mathrm{P}$ & EG & VP \\
\hline$s_{2}^{1}, s_{1}^{2}, s_{1}^{3}$ & $\mathrm{~F}$ & $\mathrm{EP}$ & VG & $\mathrm{P}$ & G & MG & $\mathrm{P}$ & $\mathrm{MP}$ & MG & $\mathrm{F}$ & MG & VG \\
\hline$s_{3}^{1}, s_{1}^{2}, s_{1}^{3}$ & EG & MP & $\mathrm{EP}$ & G & MG & VG & $\mathrm{EP}$ & $\mathrm{P}$ & VP & $\mathrm{P}$ & $\mathrm{P}$ & MG \\
\hline$s_{1}^{1}, s_{2}^{2}, s_{1}^{3}$ & EG & F & G & EG & MG & VP & VG & G & MP & $\mathrm{F}$ & $\mathrm{F}$ & EG \\
\hline$s_{2}^{1}, s_{2}^{2}, s_{1}^{3}$ & EP & MP & VP & G & $\mathrm{EG}$ & MP & $\mathrm{P}$ & $\mathrm{F}$ & VG & G & EG & MP \\
\hline$s_{3}^{1}, s_{2}^{2}, s_{1}^{3}$ & $\mathrm{EG}$ & MG & MG & $\mathrm{P}$ & $\mathrm{P}$ & G & G & $\mathrm{EP}$ & VP & $\mathrm{P}$ & MP & VP \\
\hline$s_{1}^{1}, s_{3}^{2}, s_{1}^{3}$ & G & EG & MG & EG & MP & $\mathrm{F}$ & $\mathrm{F}$ & $\mathrm{P}$ & G & G & EG & MG \\
\hline$s_{2}^{1}, s_{3}^{2}, s_{1}^{3}$ & $\mathrm{P}$ & EG & MG & EG & MG & VG & VP & MG & $\mathrm{EP}$ & G & EG & $\mathrm{P}$ \\
\hline$s_{3}^{1}, s_{3}^{2}, s_{1}^{3}$ & $\mathrm{G}$ & G & $\mathrm{F}$ & $\mathrm{EP}$ & $\mathrm{F}$ & EG & G & $\mathrm{F}$ & $\mathrm{F}$ & $\mathrm{EP}$ & $\mathrm{P}$ & VG \\
\hline$s_{1}^{1}, s_{1}^{2}, s_{2}^{3}$ & EG & $\mathrm{F}$ & VG & $\mathrm{F}$ & EG & VP & EG & $\mathrm{MG}$ & $\mathrm{P}$ & $\mathrm{EG}$ & G & MG \\
\hline$s_{2}^{1}, s_{1}^{2}, s_{2}^{3}$ & EG & MG & VP & G & G & MG & EG & $\mathrm{F}$ & VG & $\mathrm{EG}$ & $\mathrm{F}$ & VP \\
\hline$s_{3}^{1}, s_{1}^{2}, s_{2}^{3}$ & G & MP & MG & $\mathrm{P}$ & F & MG & G & MG & MG & $\mathrm{P}$ & MG & MP \\
\hline$s_{1}^{1}, s_{2}^{2}, s_{2}^{3}$ & EP & MG & MG & G & $\mathrm{EP}$ & G & G & $\mathrm{MP}$ & $\mathrm{F}$ & G & MG & EG \\
\hline$s_{2}^{1}, s_{2}^{2}, s_{2}^{3}$ & EP & MG & VG & G & MG & EP & $\mathrm{EP}$ & G & MG & MP & MG & VG \\
\hline$s_{3}^{1}, s_{2}^{2}, s_{2}^{3}$ & EG & $\mathrm{F}$ & VG & $\mathrm{EP}$ & $\mathrm{EP}$ & $\mathrm{P}$ & MP & G & MP & G & G & VG \\
\hline$s_{1}^{1}, s_{3}^{2}, s_{2}^{3}$ & G & $\mathrm{EP}$ & VP & G & $\mathrm{F}$ & G & VG & $\mathrm{F}$ & $\mathrm{P}$ & EG & $\mathrm{EP}$ & EG \\
\hline$s_{2}^{1}, s_{3}^{2}, s_{2}^{3}$ & G & G & MG & EG & $\mathrm{P}$ & MG & $\mathrm{P}$ & $\mathrm{P}$ & MP & EG & EG & EP \\
\hline$s_{3}^{1}, s_{3}^{2}, s_{2}^{3}$ & EP & MP & MP & G & MG & VG & $\mathrm{F}$ & EG & $\mathrm{F}$ & $\mathrm{EP}$ & EP & MG \\
\hline
\end{tabular}

of each strategy for player $\delta$ can be formulated as a linear programming model as follows:

$\operatorname{Max} v^{\delta}$

subject to $\Psi_{\left(s_{1}^{1}, s_{1}^{2}, \ldots, s_{1}^{\delta}, \ldots, s_{1}^{\nu}\right)} * \Phi_{1}^{\delta}+\Psi_{\left(s_{1}^{1}, s_{1}^{2}, \ldots, s_{2}^{\delta}, \ldots, s_{1}^{v}\right)} * \Phi_{2}^{\delta}$

$$
\begin{gathered}
+\cdots+\Psi_{\left(s_{1}^{1}, s_{1}^{2}, \ldots, s_{m_{\delta}}^{\delta}, \ldots, s_{1}^{v}\right)} * \Phi_{m_{\delta}}^{\delta} \geq v^{\delta} \\
\Psi_{\left(s_{1}^{1}, s_{1}^{2}, \ldots, s_{1}^{\delta}, \ldots, s_{2}^{v}\right)} * \Phi_{1}^{\delta}+\Psi_{\left(s_{1}^{1}, s_{1}^{2}, \ldots, s_{2}^{\delta}, \ldots, s_{2}^{v}\right)} * \Phi_{2}^{\delta} \\
+\cdots+\Psi_{\left(s_{1}^{1}, s_{1}^{2}, \ldots, s_{m_{\delta}}^{\delta}, \ldots, s_{2}^{v}\right)} * \Phi_{m_{\delta}}^{\delta} \geq v^{\delta}
\end{gathered}
$$

$\Psi_{\left(s_{m_{1}}^{1}, s_{m_{2}}^{2}, \ldots, s_{1}^{\delta}, \ldots, s_{m_{v}}^{v}\right)} * \Phi_{1}^{\delta}+\Psi_{\left(s_{m_{1}}^{1}, s_{m_{2}}^{2}, \ldots, s_{2}^{\delta}, \ldots, s_{m_{v}}^{v}\right)} * \Phi_{2}^{\delta}$ $+\cdots+\Psi_{\left(s_{m_{1}}^{1}, s_{m_{2}}^{2}, \ldots, s_{m_{\delta}}^{\delta}, \ldots, s_{m_{v}}^{v}\right)} * \Phi_{m_{\delta}}^{\delta} \geq v^{\delta}$

$\Phi_{1}^{\delta}+\Phi_{2}^{\delta}+\cdots+\Phi_{m_{\delta}}^{\delta}=1$

$\Phi_{i}^{\delta} \geq 0 ; \quad i=1,2, \ldots, m_{\delta}$ 
TABLE 4: The linguistic performance of enterprise $P^{2}$ with respect to criteria for each strategy combination.

\begin{tabular}{|c|c|c|c|c|c|c|c|c|c|}
\hline \multirow{2}{*}{$\begin{array}{l}\text { Strategy } \\
\text { combination }\end{array}$} & \multicolumn{3}{|c|}{$c_{1}^{2}$} & \multicolumn{3}{|c|}{$c_{2}^{2}$} & \multicolumn{3}{|c|}{$c_{3}^{2}$} \\
\hline & $D_{1}$ & $D_{2}$ & $D_{3}$ & $D_{1}$ & $D_{2}$ & $D_{3}$ & $D_{1}$ & $\mathrm{D}_{2}$ & $D_{3}$ \\
\hline$s_{1}^{1}, s_{1}^{2}, s_{1}^{3}$ & G & MP & VG & $G$ & $\mathrm{~F}$ & VG & $\mathrm{F}$ & EG & VG \\
\hline$s_{2}^{1}, s_{1}^{2}, s_{1}^{3}$ & $\mathrm{P}$ & EP & $\mathrm{P}$ & $\mathrm{P}$ & $\mathrm{F}$ & $\mathrm{F}$ & $\mathrm{P}$ & MG & $\mathrm{F}$ \\
\hline$s_{3}^{1}, s_{1}^{2}, s_{1}^{3}$ & G & G & $\mathrm{F}$ & $\mathrm{EP}$ & MP & $\mathrm{P}$ & $\mathrm{EP}$ & MP & MG \\
\hline$s_{1}^{1}, s_{2}^{2}, s_{1}^{3}$ & $\mathrm{P}$ & $\mathrm{F}$ & MP & $\mathrm{F}$ & MP & MP & G & MG & MP \\
\hline$s_{2}^{1}, s_{2}^{2}, s_{1}^{3}$ & $\mathrm{EP}$ & $\mathrm{P}$ & VG & G & $\mathrm{MG}$ & VG & G & EG & VP \\
\hline$s_{3}^{1}, s_{2}^{2}, s_{1}^{3}$ & EG & MP & $\mathrm{F}$ & MP & G & VP & EG & MG & EG \\
\hline$s_{1}^{1}, s_{3}^{2}, s_{1}^{3}$ & $\mathrm{EP}$ & $\mathrm{EP}$ & $\mathrm{P}$ & $\mathrm{F}$ & $\mathrm{F}$ & MG & G & EG & $\mathrm{F}$ \\
\hline$s_{2}^{1}, s_{3}^{2}, s_{1}^{3}$ & EG & G & G & $\mathrm{P}$ & G & $\mathrm{P}$ & EG & G & MP \\
\hline$s_{3}^{1}, s_{3}^{2}, s_{1}^{3}$ & G & $\mathrm{P}$ & VG & G & MP & VG & $\mathrm{P}$ & MG & VG \\
\hline$s_{1}^{1}, s_{1}^{2}, s_{2}^{3}$ & $\mathrm{P}$ & $\mathrm{F}$ & $\mathrm{P}$ & MP & MG & VP & $\mathrm{P}$ & $\mathrm{EP}$ & MG \\
\hline$s_{2}^{1}, s_{1}^{2}, s_{2}^{3}$ & G & MP & VG & $\mathrm{F}$ & MG & $\mathrm{G}$ & $\mathrm{F}$ & MP & VG \\
\hline$s_{3}^{1}, s_{1}^{2}, s_{2}^{3}$ & EG & G & MG & G & $\mathrm{P}$ & MG & G & MG & VP \\
\hline$s_{1}^{1}, s_{2}^{2}, s_{2}^{3}$ & $\mathrm{EG}$ & $\mathrm{F}$ & $\mathrm{EP}$ & MP & EG & MP & $\mathrm{P}$ & G & EG \\
\hline$s_{2}^{1}, s_{2}^{2}, s_{2}^{3}$ & EG & MG & $\mathrm{VP}$ & $\mathrm{EP}$ & G & VG & $\mathrm{P}$ & MP & MP \\
\hline$s_{3}^{1}, s_{2}^{2}, s_{2}^{3}$ & $\mathrm{P}$ & MP & VP & G & EP & G & $\mathrm{F}$ & $\mathrm{P}$ & EP \\
\hline$s_{1}^{1}, s_{3}^{2}, s_{2}^{3}$ & EP & MG & G & $\mathrm{P}$ & $\mathrm{F}$ & MP & G & G & $\mathrm{P}$ \\
\hline$s_{2}^{1}, s_{3}^{2}, s_{2}^{3}$ & G & MG & G & $\mathrm{P}$ & MG & VG & G & MG & MG \\
\hline$s_{3}^{1}, s_{3}^{2}, s_{2}^{3}$ & EP & MP & VG & MP & EG & MG & EG & MP & VG \\
\hline
\end{tabular}

where $v^{\delta}$ represents the expected performance of player $\delta$ and $\Phi_{\pi}^{\delta}$ is the probability of the strategy $s_{\pi}^{\delta}$.

\section{Numerical Example}

Suppose that there are three enterprises (players) $P^{1}, P^{2}$, and $P^{3}$ who can produce high technology mobile phone in the market. Each enterprise possesses its strong point and weakness. The product development strategy and manufacture strategy of each enterprise will influence the competitive performance of other enterprises in the different dimensions. Based on R\&D ability and the brand impressions of each enterprise, the strategy of each enterprise will be limited to develop a new product. Enterprise $P^{1}$ invites three experts to analyze and select a suitable strategy for developing a new mobile phone. The first expert is a marketing director who comes from the marketing department in the enterprise. The second expert is an R\&D manager who is the project leader of the research and development department in the enterprise. The third expert is a strategy professor who is invited from the university. Enterprise $P^{1}$ has three development strategies and also knows that competitor $P^{2}$ has three strategies and competitor $P^{3}$ has two strategies for developing a new mobile phone. Enterprise $P^{1}$ considers four criteria to make a decision. Enterprise $P^{1}$ also knows that competitor $P^{2}$ considers three criteria for making decision and competitor $P^{3}$ considers four criteria for making decision. The strategies and evaluation criteria of enterprises are shown in Table 2.

According to the computational process of linguistic multiperson multi-criteria game (LMPMCG) model, the problem can be solved as follows.

\subsection{Aggregating the Evaluations of Experts}

Step 1. Each expert uses the linguistic variables to evaluate the performance of each enterprise with respect to each criterion based on different strategy combinations as Tables 3, 4, and 5.

Step 2. Transform the linguistic evaluation of the performance of each enterprise with respect to each criterion into PTFN as Tables 6, 7, and 8. And then, the performance of each enterprise with respect to each criterion can be aggregated as Table 9 .

Step 3. The aggregated performance of each enterprise with respect to each criterion can be defuzzied as Table 10 .

Step 4. Each expert uses the linguistic variables to evaluate the weight of each criterion as Table 11.

Step 5. Transform the linguistic evaluation of the weight of each criterion into PTFN as Table 12. And then, the aggregated weight of each criterion can be computed as Table 12.

Step 6. The aggregated weight of each criterion can be defuzzied as Table 12.

4.2. Analysis of Mixed Strategy. After aggregating the evaluations of experts, the optimal strategy of each enterprise can be determined by considering all strategy combinations. At first, the weighted performance of each strategy combination based on the opinions of experts must be calculated. And then, the optimal probability of each strategy for each 
TABLE 5: The linguistic performance of enterprise $P^{3}$ with respect to criteria for each strategy combination.

\begin{tabular}{|c|c|c|c|c|c|c|c|c|c|c|c|c|}
\hline \multirow{2}{*}{$\begin{array}{l}\text { Strategy } \\
\text { combination }\end{array}$} & \multicolumn{3}{|c|}{$c_{1}^{3}$} & \multicolumn{3}{|c|}{$c_{2}^{3}$} & \multicolumn{3}{|c|}{$c_{3}^{3}$} & \multicolumn{3}{|c|}{$c_{4}^{3}$} \\
\hline & $D_{1}$ & $\mathrm{D}_{2}$ & $D_{3}$ & $D_{1}$ & $\mathrm{D}_{2}$ & $D_{3}$ & $D_{1}$ & $\mathrm{D}_{2}$ & $D_{3}$ & $D_{1}$ & $\mathrm{D}_{2}$ & $D_{3}$ \\
\hline$s_{1}^{1}, s_{1}^{2}, s_{1}^{3}$ & $\mathrm{P}$ & MP & $\mathrm{F}$ & $\mathrm{P}$ & $\mathrm{F}$ & $\mathrm{F}$ & $\mathrm{P}$ & $\mathrm{EP}$ & MP & $G$ & MP & $\mathrm{P}$ \\
\hline$s_{2}^{1}, s_{1}^{2}, s_{1}^{3}$ & G & MP & $\mathrm{MP}$ & G & G & VG & G & MP & VG & $\mathrm{F}$ & G & VG \\
\hline$s_{3}^{1}, s_{1}^{2}, s_{1}^{3}$ & $\mathrm{EP}$ & G & F & G & $\mathrm{P}$ & G & $\mathrm{F}$ & F & G & EG & MG & $\mathrm{P}$ \\
\hline$s_{1}^{1}, s_{2}^{2}, s_{1}^{3}$ & $\mathrm{~F}$ & MG & MG & EG & MG & VP & G & F & VP & $\mathrm{P}$ & $\mathrm{EG}$ & VG \\
\hline$s_{2}^{1}, s_{2}^{2}, s_{1}^{3}$ & $\mathrm{EG}$ & $\mathrm{P}$ & $\mathrm{P}$ & $\mathrm{F}$ & MG & G & $\mathrm{F}$ & $\mathrm{F}$ & G & G & $\mathrm{F}$ & MP \\
\hline$s_{3}^{1}, s_{2}^{2}, s_{1}^{3}$ & $\mathrm{~F}$ & $\mathrm{P}$ & VG & EG & EG & VG & EG & $\mathrm{F}$ & MG & $\mathrm{F}$ & G & VP \\
\hline$s_{1}^{1}, s_{3}^{2}, s_{1}^{3}$ & $\mathrm{P}$ & EG & VP & $\mathrm{F}$ & MG & MG & EG & MP & VP & $\mathrm{P}$ & $\mathrm{P}$ & $\mathrm{P}$ \\
\hline$s_{2}^{1}, s_{3}^{2}, s_{1}^{3}$ & G & MP & MP & $\mathrm{P}$ & F & $\mathrm{P}$ & $\mathrm{P}$ & MG & $\mathrm{P}$ & G & MG & G \\
\hline$s_{3}^{1}, s_{3}^{2}, s_{1}^{3}$ & $\mathrm{EP}$ & EG & G & G & $\mathrm{P}$ & MG & G & $\mathrm{P}$ & VG & G & G & MG \\
\hline$s_{1}^{1}, s_{1}^{2}, s_{2}^{3}$ & EG & G & MP & $\mathrm{F}$ & G & VG & F & MG & G & EG & $\mathrm{F}$ & VG \\
\hline$s_{2}^{1}, s_{1}^{2}, s_{2}^{3}$ & $\mathrm{P}$ & $\mathrm{P}$ & $\mathrm{VP}$ & G & $\mathrm{EP}$ & $\mathrm{P}$ & G & $\mathrm{MP}$ & MG & $\mathrm{P}$ & G & G \\
\hline$s_{3}^{1}, s_{1}^{2}, s_{2}^{3}$ & G & $\mathrm{EP}$ & $\mathrm{P}$ & G & $\mathrm{F}$ & G & EG & G & $\mathrm{F}$ & G & MG & VP \\
\hline$s_{1}^{1}, s_{2}^{2}, s_{2}^{3}$ & $\mathrm{~F}$ & MG & VG & $\mathrm{EG}$ & MG & EG & $\mathrm{P}$ & $\mathrm{F}$ & MG & $\mathrm{F}$ & $\mathrm{MP}$ & $\mathrm{P}$ \\
\hline$s_{2}^{1}, s_{2}^{2}, s_{2}^{3}$ & $\mathrm{P}$ & $\mathrm{F}$ & $\mathrm{P}$ & $\mathrm{F}$ & $\mathrm{EG}$ & VP & G & EG & $\mathrm{VP}$ & EP & $\mathrm{F}$ & $\mathrm{P}$ \\
\hline$s_{3}^{1}, s_{2}^{2}, s_{2}^{3}$ & EG & MP & VP & $\mathrm{EP}$ & MG & MP & $\mathrm{EP}$ & $\mathrm{P}$ & EG & EG & $\mathrm{EP}$ & G \\
\hline$s_{1}^{1}, s_{3}^{2}, s_{2}^{3}$ & G & G & $\mathrm{P}$ & EG & G & MG & $\mathrm{F}$ & $\mathrm{EP}$ & MG & G & $\mathrm{F}$ & MG \\
\hline$s_{2}^{1}, s_{3}^{2}, s_{2}^{3}$ & G & G & MG & G & MG & EG & G & $\mathrm{F}$ & MP & EG & MP & VG \\
\hline$s_{3}^{1}, s_{3}^{2}, s_{2}^{3}$ & $\mathrm{~F}$ & MP & VP & $\mathrm{P}$ & $\mathrm{EP}$ & VP & EG & MP & G & EP & $\mathrm{P}$ & $\mathrm{F}$ \\
\hline
\end{tabular}

enterprise can be formulated by a linear programming model. Finally, the occurrence probability of each strategy combination can be computed by solving the linear programming model. The computational steps can be illustrated as follows.

Step 1. For any strategy combination, the weighted performance of each enterprise with respect to each criterion can be calculated as Table 13 .

Step 2. Calculate the aggregated performance of each enterprise with respect to all criteria for any strategy combination.

Step 3. The aggregated performance of each enterprise for the strategy combination can be arranged as a multiperson multi-criteria noncooperation game as Table 14. According to Table 14, the performance of enterprise $P^{1}$ is 0.5254 when enterprise $P^{1}$ chooses strategy $s_{1}^{1}$, enterprise $P^{2}$ chooses strategy $s_{1}^{2}$, and enterprise $P^{3}$ chooses strategy $s_{1}^{3}$. The performance of enterprise $P^{1}$ is 0.5354 when enterprise $P^{1}$ chooses strategy $s_{2}^{1}$, enterprise $P^{2}$ chooses strategy $s_{1}^{2}$, and enterprise $P^{3}$ chooses strategy $s_{1}^{3}$. The performance of enterprise $P^{1}$ is 0.4821 when enterprise $P^{1}$ chooses strategy $s_{3}^{1}$, enterprise $P^{2}$ chooses strategy $s_{1}^{2}$, and enterprise $P^{3}$ chooses strategy $s_{1}^{3}$. Based on the strategy combinations in game model, the larger aggregated performance is the better strategy for the enterprise.

Step 4. Under the competitive situation, each enterprise hopes that the overall performance is higher than other enterprises as the probability of each strategy is computed. Therefore, the expected performance of the mixed strategy of each enterprise should be higher than the performance of each enterprise although the strategies are selected by other enterprises. According to the aggregated performances of all strategies, enterprise $P^{1}$ will maximize the expected performance by formulating a linear programming model as follows:

$$
\begin{array}{ll}
\operatorname{Max} v^{1} & \\
\text { subject to } \quad & 0.5254 * \Phi_{1}^{1}+0.5354 * \Phi_{2}^{1} \\
& +0.4821 * \Phi_{3}^{1} \geq v^{1} ; \\
& 0.6706 * \Phi_{1}^{1}+0.6365 * \Phi_{2}^{1} \\
& +0.5135 * \Phi_{3}^{1} \geq v^{1} ; \\
& 0.6501 * \Phi_{1}^{1}+0.5338 * \Phi_{2}^{1} \\
& +0.4422 * \Phi_{3}^{1} \geq v^{1} ; \\
& 0.5629 * \Phi_{1}^{1}+0.5220 * \Phi_{2}^{1} \\
& +0.5216 * \Phi_{3}^{1} \geq v^{1} ; \\
& 0.6804 * \Phi_{1}^{1}+0.6352 * \Phi_{2}^{1} \\
& +0.5292 * \Phi_{3}^{1} \geq v^{1} ; \\
& \\
& \\
& \\
& \\
& 0.5475 * \Phi_{1}^{1}+0.5978 * \Phi_{2}^{1} \\
&
\end{array}
$$




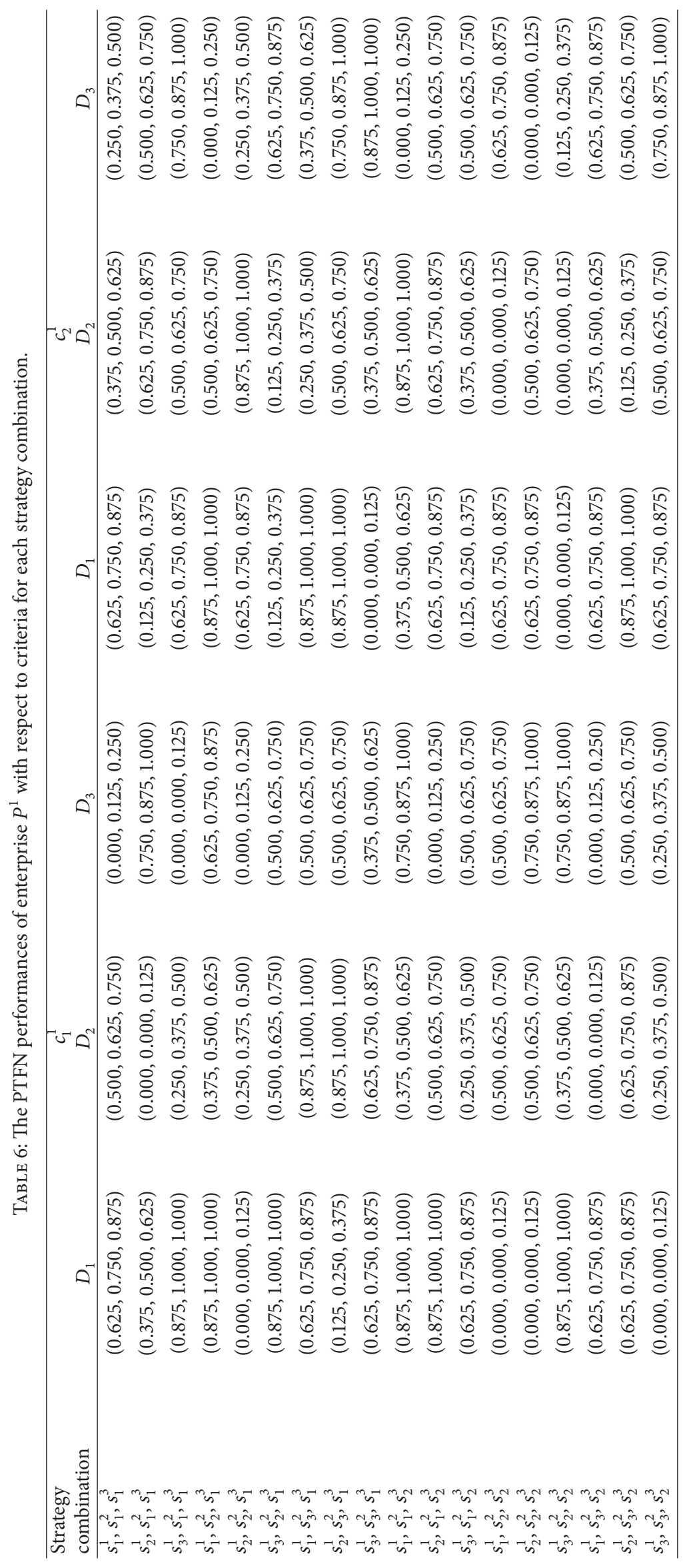




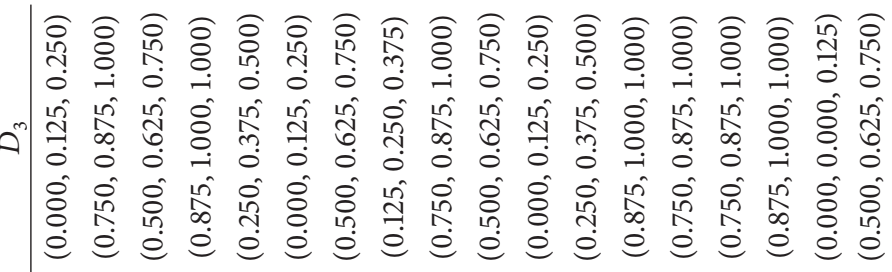

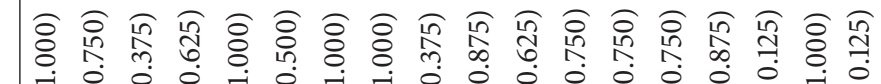
^)

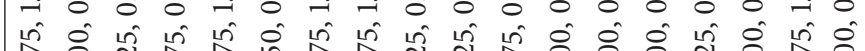

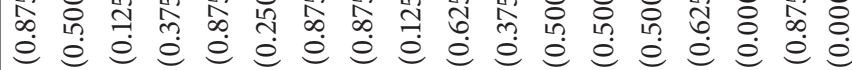

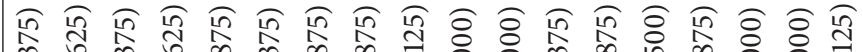

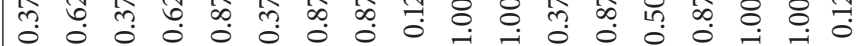

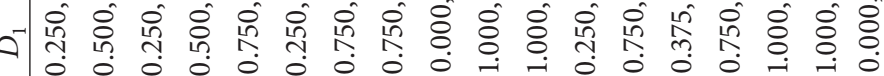
(n)

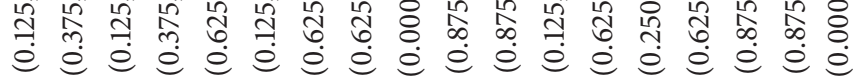

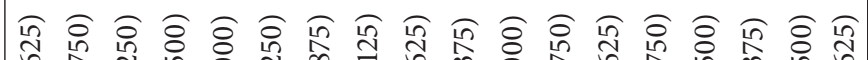

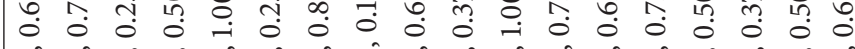
๙

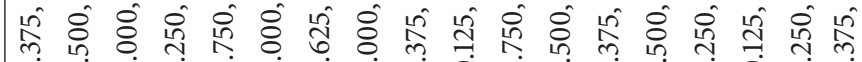

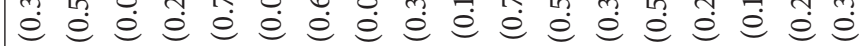

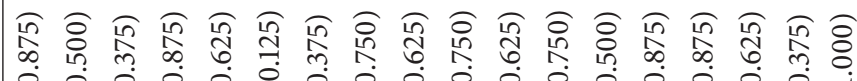

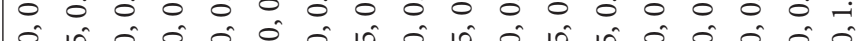

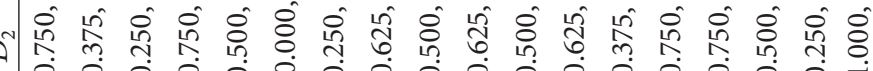

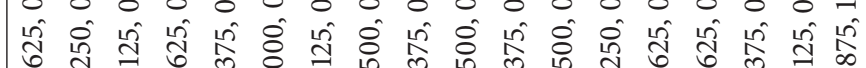

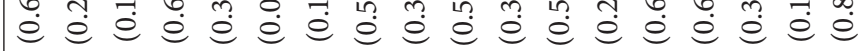

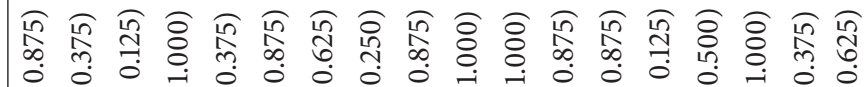

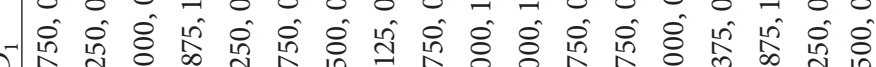

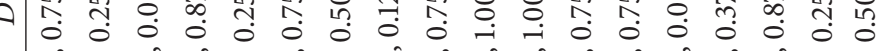

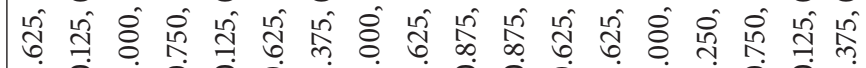

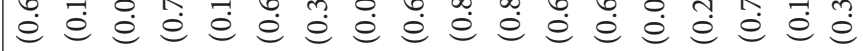




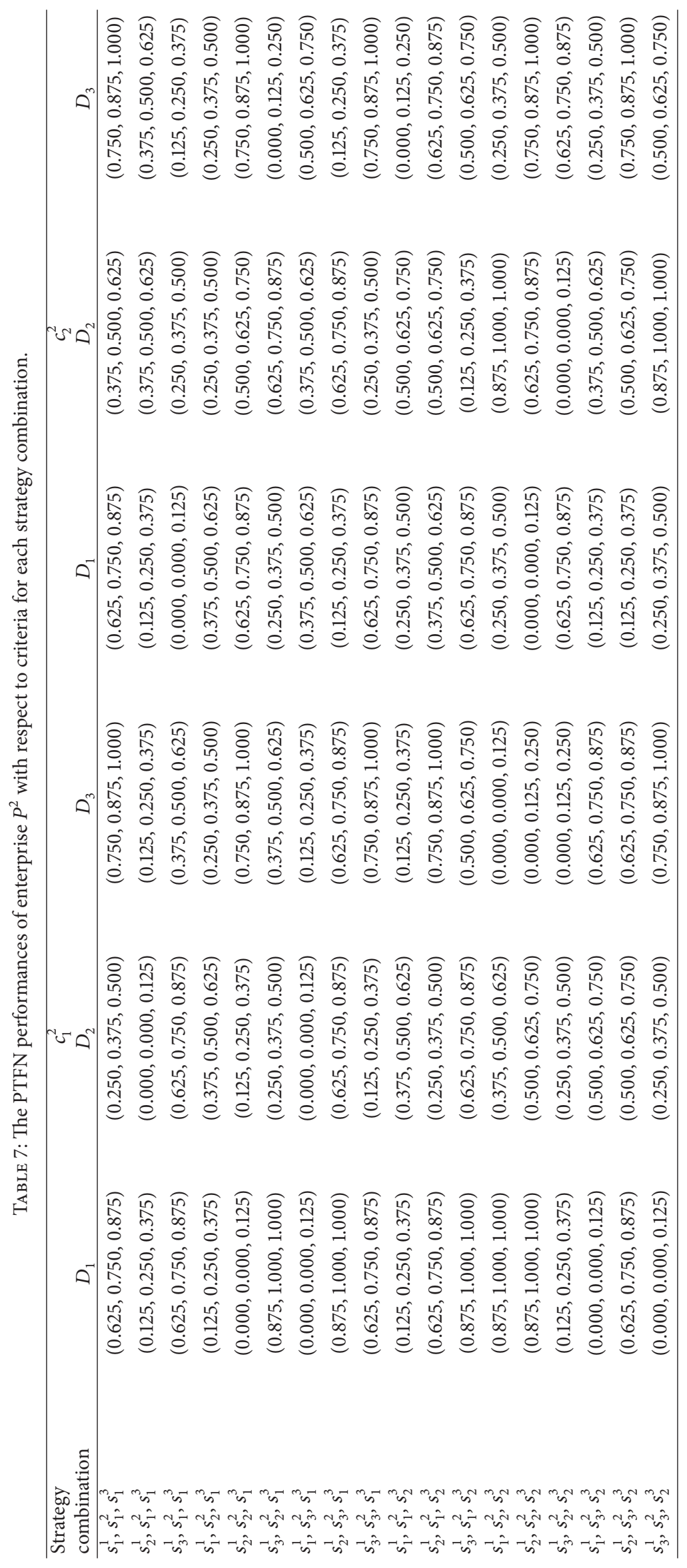




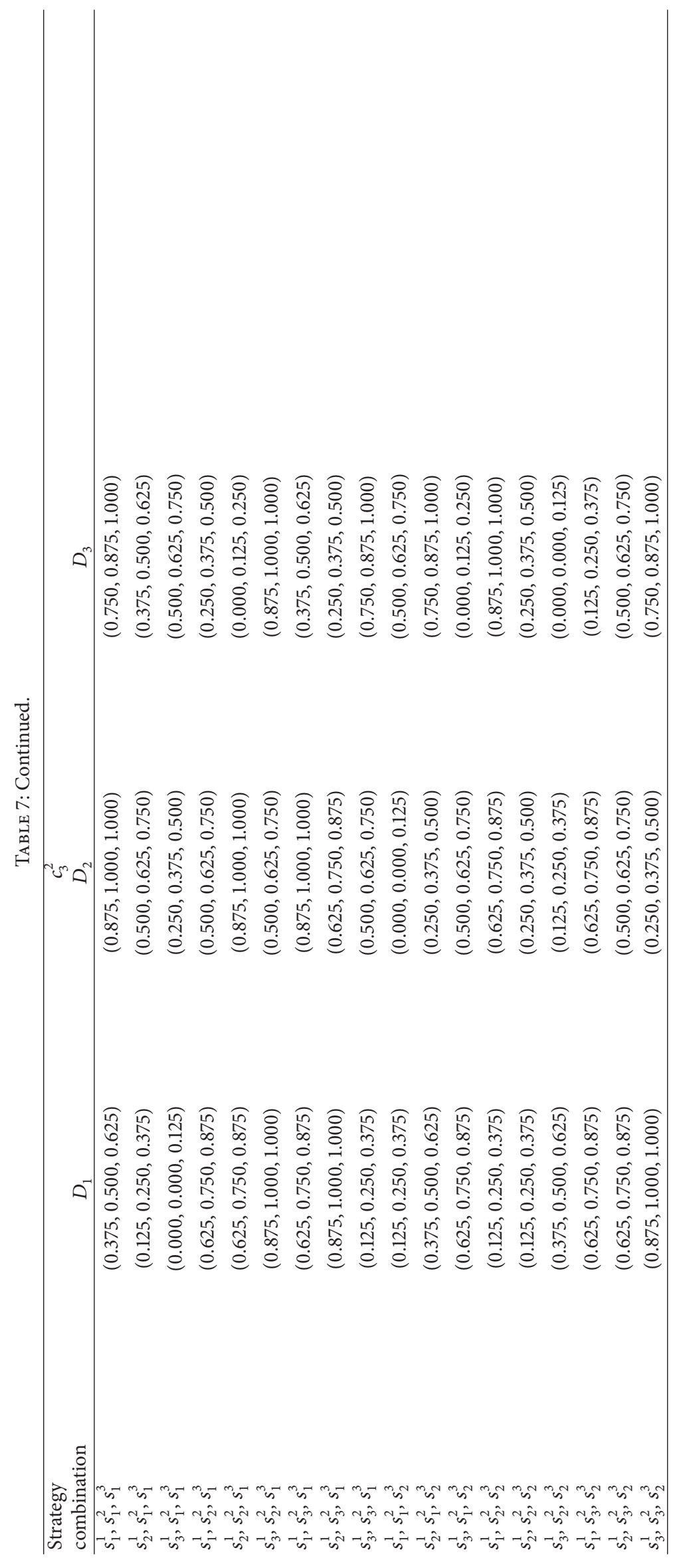




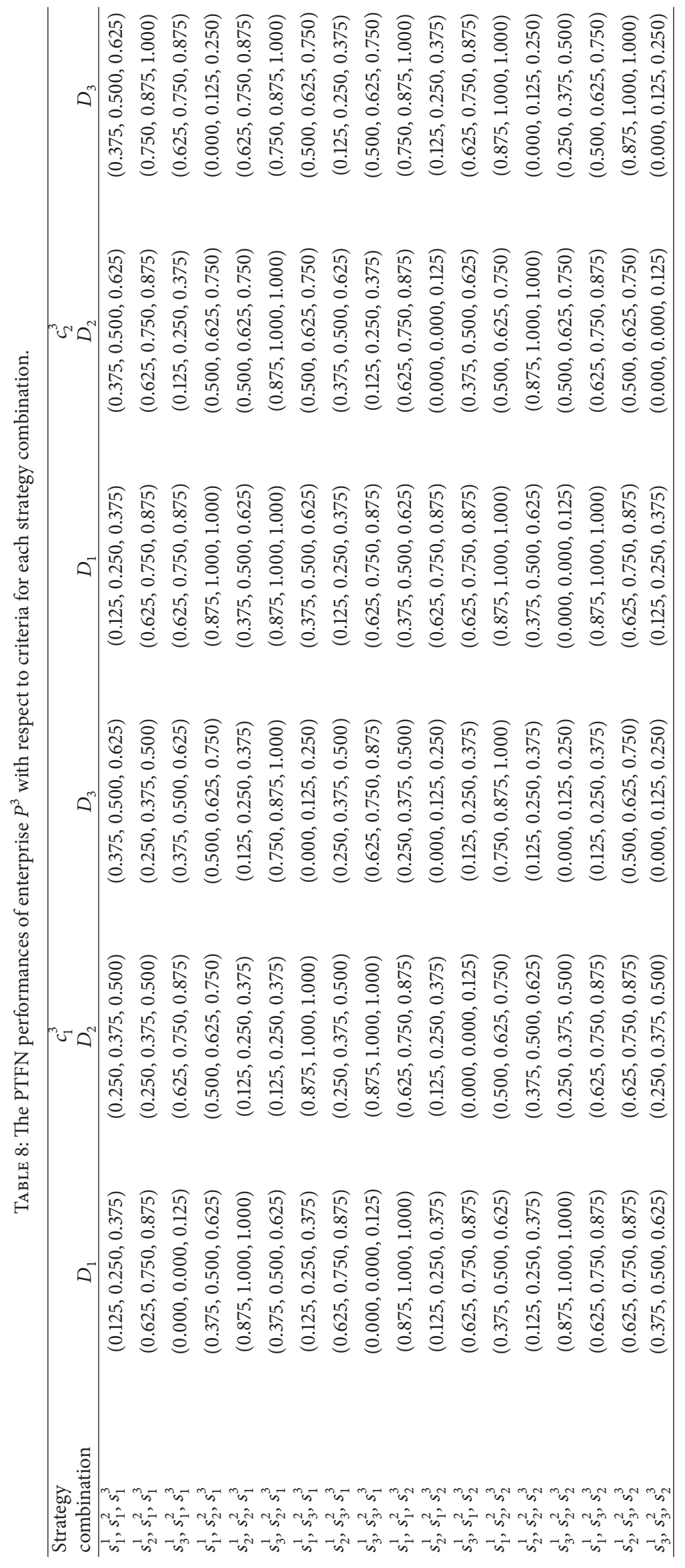




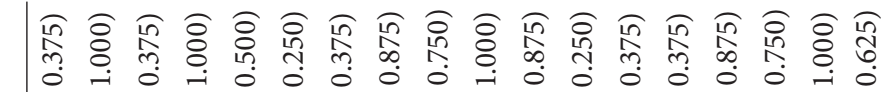
m

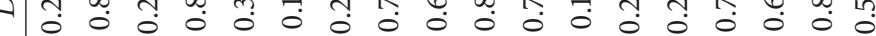

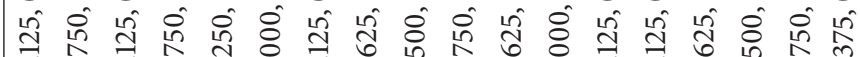

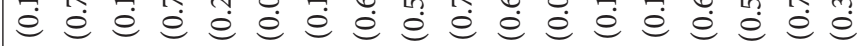

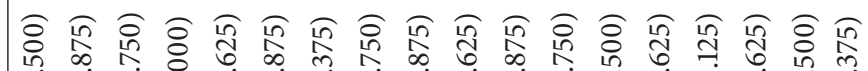

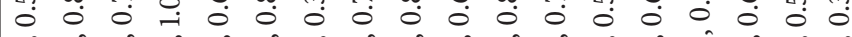

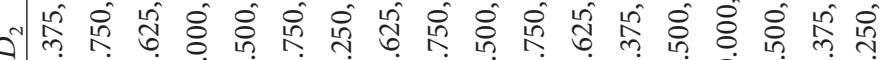

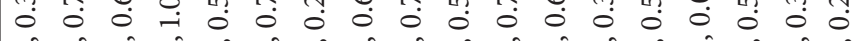

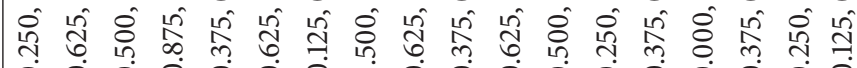

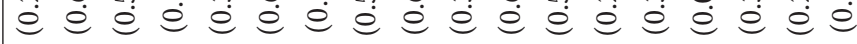

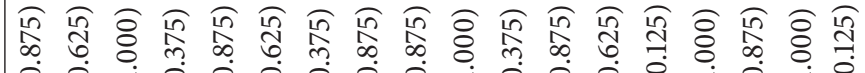

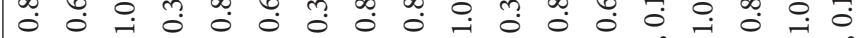

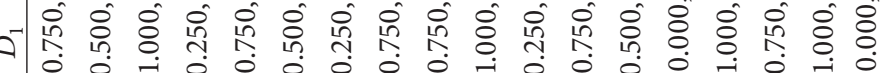

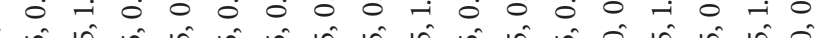
约 众

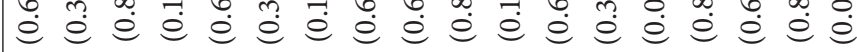

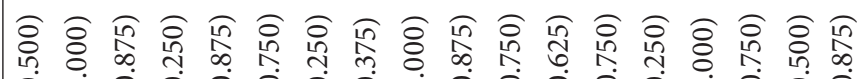
n ๙

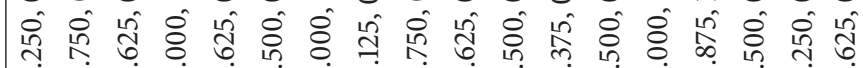

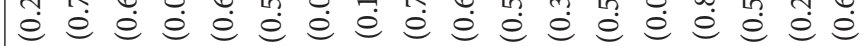

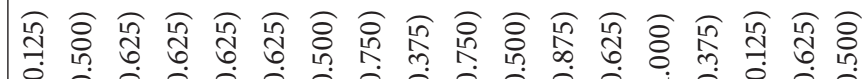

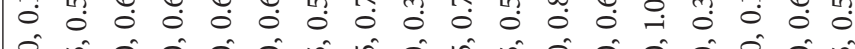

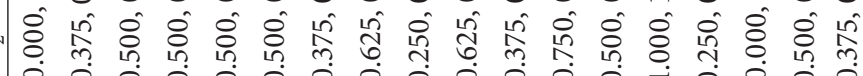

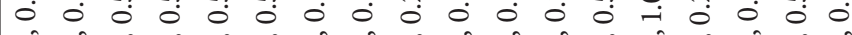

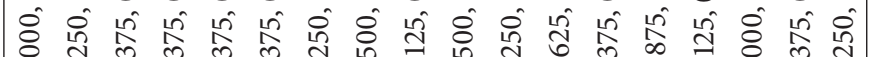

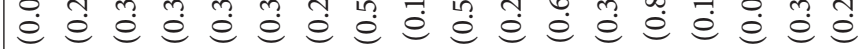

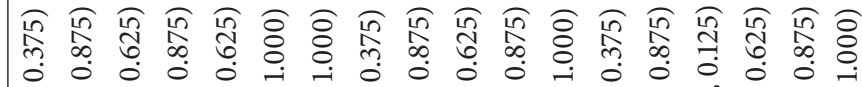

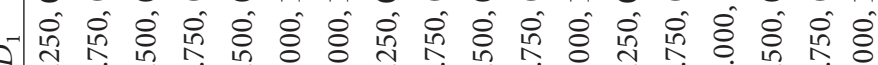

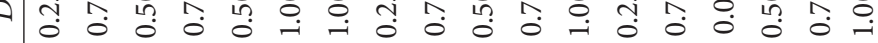

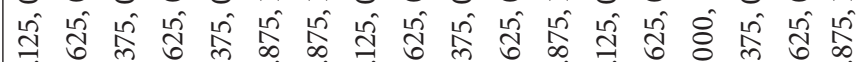

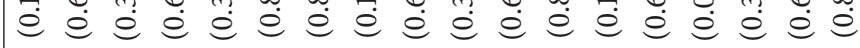




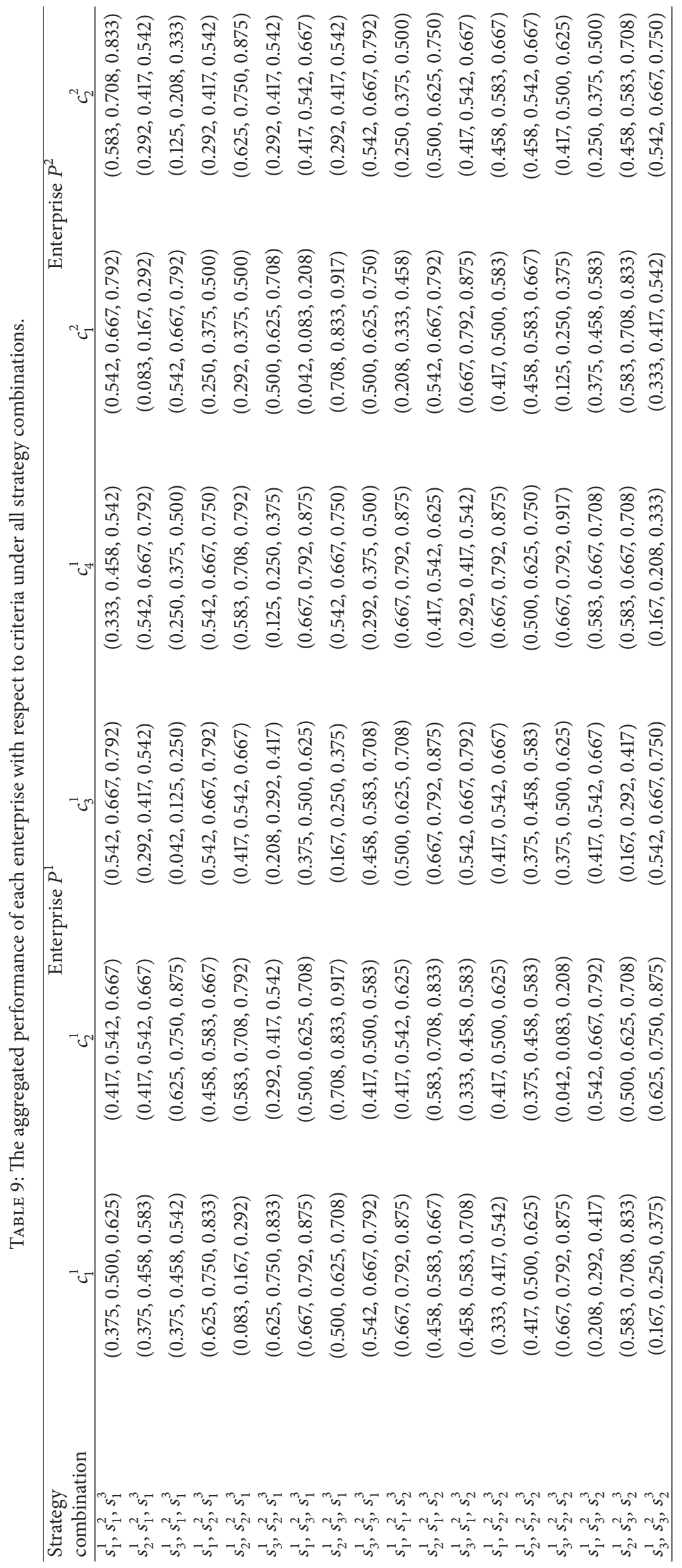




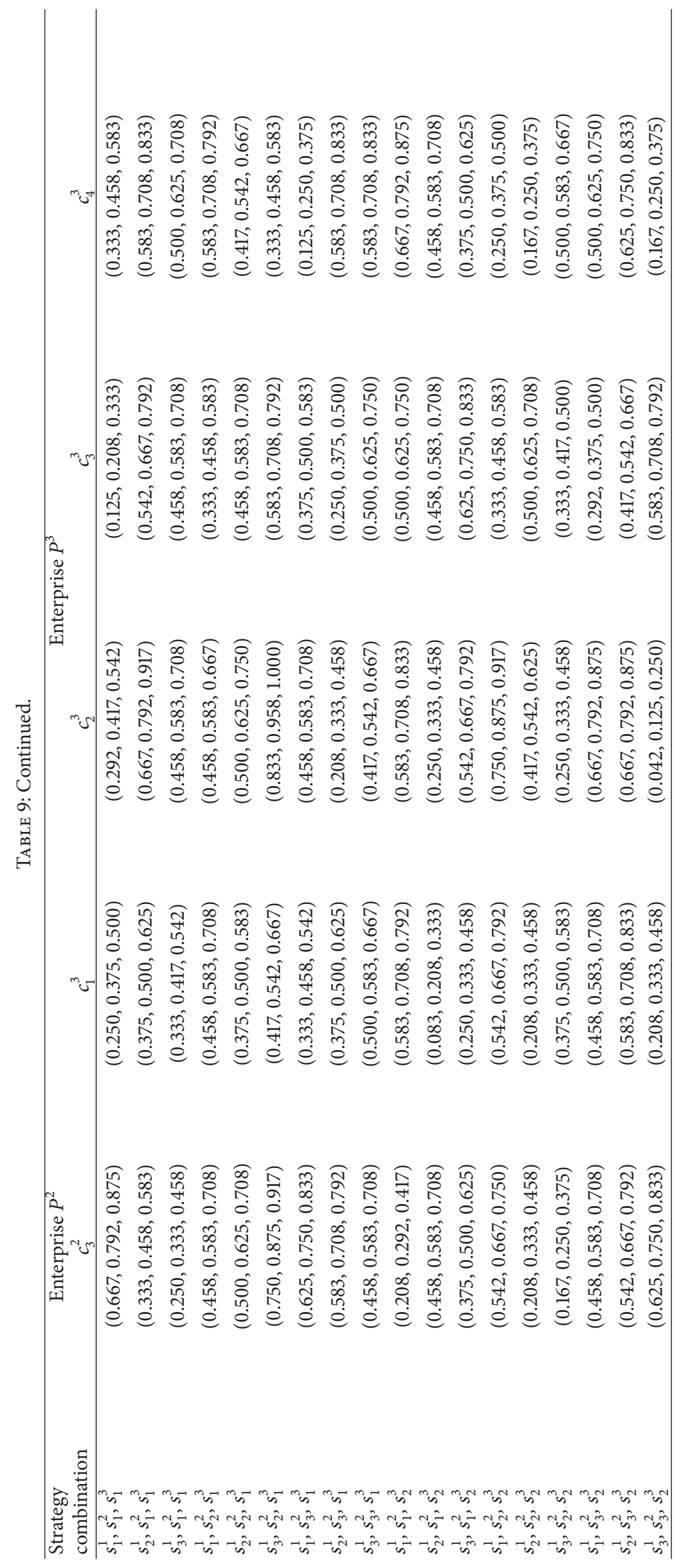


TABLE 10: The defuzzied performance of each enterprise with respect to criteria under all strategy combinations.

\begin{tabular}{lccccccccccc}
\hline $\begin{array}{l}\text { Strategy } \\
\text { combination }\end{array}$ & \multicolumn{3}{c}{$c_{1}^{1}$} & $c_{2}^{1}$ & $c_{3}^{1}$ & $c_{4}^{1}$ & $c_{1}^{2}$ & $c_{2}^{2}$ & $c_{3}^{2}$ & $c_{1}^{3}$ & \multicolumn{2}{c}{ Enterprise $P^{3}$} & $c_{3}^{3}$ \\
& 0.500 & 0.542 & 0.667 & 0.444 & 0.667 & 0.708 & 0.778 & 0.375 & 0.417 & 0.222 & 0.458 \\
$s_{1}^{1}, s_{1}^{2}, s_{1}^{3}$ & 0.472 & 0.542 & 0.417 & 0.667 & 0.181 & 0.417 & 0.458 & 0.500 & 0.792 & 0.667 & 0.708 \\
$s_{2}^{1}, s_{1}^{2}, s_{1}^{3}$ & 0.458 & 0.750 & 0.139 & 0.375 & 0.667 & 0.222 & 0.347 & 0.431 & 0.583 & 0.583 & 0.611 \\
$s_{3}^{1}, s_{1}^{2}, s_{1}^{3}$ & 0.736 & 0.569 & 0.667 & 0.653 & 0.375 & 0.417 & 0.583 & 0.583 & 0.569 & 0.458 & 0.694 \\
$s_{1}^{1}, s_{2}^{2}, s_{1}^{3}$ & 0.181 & 0.694 & 0.542 & 0.694 & 0.389 & 0.750 & 0.611 & 0.486 & 0.625 & 0.583 & 0.542 \\
$s_{2}^{1}, s_{2}^{2}, s_{1}^{3}$ & 0.736 & 0.417 & 0.306 & 0.250 & 0.611 & 0.417 & 0.847 & 0.542 & 0.931 & 0.694 & 0.458 \\
$s_{3}^{1}, s_{2}^{2}, s_{1}^{3}$ & 0.778 & 0.611 & 0.500 & 0.778 & 0.111 & 0.542 & 0.736 & 0.444 & 0.583 & 0.486 & 0.250 \\
$s_{1}^{1}, s_{3}^{2}, s_{1}^{3}$ & 0.611 & 0.819 & 0.264 & 0.653 & 0.819 & 0.417 & 0.694 & 0.500 & 0.333 & 0.375 & 0.708 \\
$s_{2}^{1}, s_{3}^{2}, s_{1}^{3}$ & 0.667 & 0.500 & 0.583 & 0.389 & 0.625 & 0.667 & 0.583 & 0.583 & 0.542 & 0.625 & 0.708 \\
$s_{3}^{1}, s_{3}^{2}, s_{1}^{3}$ & 0.778 & 0.528 & 0.611 & 0.778 & 0.333 & 0.375 & 0.306 & 0.694 & 0.708 & 0.625 & 0.778 \\
$s_{1}^{1}, s_{1}^{2}, s_{2}^{3}$ & 0.569 & 0.708 & 0.778 & 0.528 & 0.667 & 0.625 & 0.583 & 0.208 & 0.347 & 0.583 & 0.583 \\
$s_{2}^{1}, s_{1}^{2}, s_{2}^{3}$ & 0.583 & 0.458 & 0.667 & 0.417 & 0.778 & 0.542 & 0.500 & 0.347 & 0.667 & 0.736 & 0.500 \\
$s_{3}^{1}, s_{1}^{2}, s_{2}^{3}$ & 0.431 & 0.514 & 0.542 & 0.778 & 0.500 & 0.569 & 0.653 & 0.667 & 0.847 & 0.458 & 0.375 \\
$s_{1}^{1}, s_{2}^{2}, s_{2}^{3}$ & 0.514 & 0.472 & 0.472 & 0.625 & 0.569 & 0.556 & 0.333 & 0.333 & 0.528 & 0.611 & 0.264 \\
$s_{2}^{1}, s_{2}^{2}, s_{2}^{3}$ & 0.778 & 0.111 & 0.500 & 0.792 & 0.250 & 0.514 & 0.264 & 0.486 & 0.347 & 0.417 & 0.583 \\
$s_{3}^{1}, s_{2}^{2}, s_{2}^{3}$ & 0.306 & 0.667 & 0.542 & 0.653 & 0.472 & 0.375 & 0.583 & 0.583 & 0.778 & 0.389 & 0.625 \\
$s_{1}^{1}, s_{3}^{2}, s_{2}^{3}$ & 0.708 & 0.611 & 0.292 & 0.653 & 0.708 & 0.583 & 0.667 & 0.708 & 0.778 & 0.542 & 0.736 \\
$s_{2}^{1}, s_{3}^{2}, s_{2}^{3}$ & 0.264 & 0.750 & 0.653 & 0.236 & 0.431 & 0.653 & 0.736 & 0.333 & 0.139 & 0.694 & 0.264 \\
$s_{3}^{1}, s_{3}^{2}, s_{2}^{3}$ & & & & & & & & &
\end{tabular}

TABLE 11: The linguistic weight of each criterion.

\begin{tabular}{cccccccccccc}
\hline \multicolumn{4}{c}{ Enterprise $P^{1}$} & \multicolumn{4}{c}{ Enterprise $P^{2}$} & \multicolumn{4}{c}{ Enterprise $P^{3}$} \\
& $c_{1}^{1}$ & $c_{2}^{1}$ & $c_{3}^{1}$ & $c_{4}^{1}$ & $c_{1}^{2}$ & $c_{2}^{2}$ & $c_{3}^{2}$ & $c_{1}^{3}$ & $c_{2}^{3}$ & $c_{3}^{3}$ & $c_{4}^{3}$ \\
\hline$D_{1}$ & $\mathrm{EH}$ & $\mathrm{EH}$ & $\mathrm{L}$ & $\mathrm{F}$ & $\mathrm{H}$ & $\mathrm{EH}$ & $\mathrm{L}$ & $\mathrm{EH}$ & $\mathrm{F}$ & $\mathrm{L}$ & $\mathrm{F}$ \\
$D_{2}$ & $\mathrm{ML}$ & $\mathrm{MH}$ & $\mathrm{F}$ & $\mathrm{L}$ & $\mathrm{H}$ & $\mathrm{ML}$ & $\mathrm{MH}$ & $\mathrm{H}$ & $\mathrm{MH}$ & $\mathrm{F}$ & $\mathrm{H}$ \\
$\mathrm{D}_{3}$ & $\mathrm{ML}$ & $\mathrm{F}$ & $\mathrm{L}$ & $\mathrm{VH}$ & $\mathrm{EH}$ & $\mathrm{MH}$ & $\mathrm{ML}$ & $\mathrm{F}$ & $\mathrm{H}$ & $\mathrm{EH}$ & $\mathrm{VH}$ \\
\hline
\end{tabular}

$$
\begin{aligned}
& \Phi_{1}^{1}+\Phi_{2}^{1}+\Phi_{3}^{1}=1 ; \\
& \Phi_{1}^{1} \geq 0 ; \\
& \Phi_{2}^{1} \geq 0 ; \\
& \Phi_{3}^{1} \geq 0 .
\end{aligned}
$$

By solving this linear programming model, the optimal probability of strategies $s_{1}^{1}, s_{2}^{1}$, and $s_{3}^{1}$ are $\Phi_{1}^{1}=0.2632, \Phi_{2}^{1}=$ 0.7368 , and $\Phi_{3}^{1}=0.0000$, respectively.

According to the aggregated performances of all strategies, enterprise $P^{2}$ will maximize the expected performance by formulating a linear programming model as follows:

$$
\begin{array}{cc}
\operatorname{Max} v^{2} & \\
\text { subject to } & 0.7056 * \Phi_{1}^{2}+0.4354 * \Phi_{2}^{2} \\
& +0.3978 * \Phi_{3}^{2} \geq v^{2} ; \\
& 0.3416 * \Phi_{1}^{2}+0.5577 * \Phi_{2}^{2}
\end{array}
$$

$$
\begin{aligned}
& +0.4631 * \Phi_{3}^{2} \geq v^{2} ; \\
& 0.3234 * \Phi_{1}^{2}+0.5627 * \Phi_{2}^{2} \\
& +0.6527 * \Phi_{3}^{2} \geq v^{2} ; \\
& 0.6339 * \Phi_{1}^{2}+0.5126 * \Phi_{2}^{2} \\
& \quad+0.6559 * \Phi_{3}^{2} \geq v^{2} ; \\
& 0.4426 * \Phi_{1}^{2}+0.5960 * \Phi_{2}^{2} \\
& \quad+0.6302 * \Phi_{3}^{2} \geq v^{2} ; \\
& 0.6349 * \Phi_{1}^{2}+0.3443 * \Phi_{2}^{2} \\
& \quad+0.5748 * \Phi_{3}^{2} \geq v^{2} ; \\
& \Phi_{1}^{2}+\Phi_{2}^{2}+\Phi_{3}^{2}=1 ; \\
& \Phi_{1}^{2} \geq 0 ; \\
& \Phi_{2}^{2} \geq 0 ; \\
& \Phi_{3}^{2} \geq 0
\end{aligned}
$$

By solving this linear programming model, the optimal probability of strategies $s_{1}^{2}, s_{2}^{2}, s_{3}^{2}$ are $\Phi_{1}^{2}=0.2136, \Phi_{2}^{2}=$ 0.4629 , and $\Phi_{3}^{2}=0.3235$, respectively.

According to the aggregated performances of all strategies, enterprise $P^{3}$ will maximize the expected performance by formulating a linear programming model as follows: 
TABLE 12: The PTFN information of each criterion.

\begin{tabular}{|c|c|c|c|c|}
\hline & \multicolumn{4}{|c|}{ Enterprise $P^{1}$} \\
\hline & $c_{1}^{1}$ & $c_{2}^{1}$ & $c_{3}^{1}$ & $c_{4}^{1}$ \\
\hline$D_{1}$ & $(0.875,1.000,1.000)$ & $(0.875,1.000,1.000)$ & $(0.125,0.250,0.375)$ & $(0.375,0.500,0.625)$ \\
\hline $\mathrm{D}_{2}$ & $(0.250,0.375,0.500)$ & $(0.500,0.625,0.750)$ & $(0.375,0.500,0.625)$ & $(0.125,0.250,0.375)$ \\
\hline$D_{3}$ & $(0.250,0.375,0.500)$ & $(0.375,0.500,0.625)$ & $(0.125,0.250,0.375)$ & $(0.750,0.875,1.000)$ \\
\hline The integrated opinions & $(0.458,0.583,0.667)$ & $(0.583,0.708,0.792)$ & $(0.208,0.333,0.458)$ & $(0.417,0.542,0.667)$ \\
\hline The defuzzied opinions & 0.569 & 0.694 & 0.333 & 0.542 \\
\hline \multicolumn{5}{|c|}{ Enterprise $P^{2}$} \\
\hline & $c_{1}^{2}$ & $c_{2}^{2}$ & $c_{3}^{2}$ & \\
\hline$\overline{D_{1}}$ & $(0.625,0.750,0.875)$ & $(0.875,1.000,1.000)$ & $(0.125,0.250,0.375)$ & \\
\hline$D_{2}$ & $(0.625,0.750,0.875)$ & $(0.250,0.375,0.500)$ & $(0.500,0.625,0.750)$ & \\
\hline$D_{3}$ & $(0.875,1.000,1.000)$ & $(0.500,0.625,0.750)$ & $(0.250,0.375,0.500)$ & \\
\hline The integrated opinions & $(0.708,0.833,0.917)$ & $(0.542,0.667,0.750)$ & $(0.292,0.417,0.542)$ & \\
\hline \multirow[t]{3}{*}{ The defuzzied opinions } & 0.819 & 0.653 & 0.417 & \\
\hline & \multicolumn{4}{|c|}{ Enterprise $P^{3}$} \\
\hline & $c_{1}^{3}$ & $c_{2}^{3}$ & $c_{3}^{3}$ & $c_{4}^{3}$ \\
\hline$\overline{D_{1}}$ & $(0.875,1.000,1.000)$ & $(0.375,0.500,0.625)$ & $(0.125,0.250,0.375)$ & $(0.375,0.500,0.625)$ \\
\hline$D_{2}$ & $(0.625,0.750,0.875)$ & $(0.500,0.625,0.750)$ & $(0.375,0.500,0.625)$ & $(0.625,0.750,0.875)$ \\
\hline$D_{3}$ & $(0.375,0.500,0.625)$ & $(0.625,0.750,0.875)$ & $(0.875,1.000,1.000)$ & $(0.750,0.875,1.000)$ \\
\hline The integrated opinions & $(0.625,0.750,0.833)$ & $(0.500,0.625,0.750)$ & $(0.458,0.583,0.667)$ & $(0.583,0.708,0.833)$ \\
\hline The defuzzied opinions & 0.736 & 0.625 & 0.569 & 0.708 \\
\hline
\end{tabular}

TABLE 13: The weighted performance of each enterprise with respect to criteria under all strategy combinations.

\begin{tabular}{|c|c|c|c|c|c|c|c|c|c|c|c|}
\hline \multirow{2}{*}{$\begin{array}{l}\text { Strategy } \\
\text { combination }\end{array}$} & \multicolumn{4}{|c|}{ Enterprise $P^{1}$} & \multicolumn{3}{|c|}{ Enterprise $P^{2}$} & \multicolumn{4}{|c|}{ Enterprise $P^{3}$} \\
\hline & $c_{1}^{1}$ & $c_{2}^{1}$ & $c_{3}^{1}$ & $c_{4}^{1}$ & $c_{1}^{2}$ & $c_{2}^{2}$ & $c_{3}^{2}$ & $c_{1}^{3}$ & $c_{2}^{3}$ & $c_{3}^{3}$ & $c_{4}^{3}$ \\
\hline$s_{1}^{1}, s_{1}^{2}, s_{1}^{3}$ & 0.1331 & 0.1759 & 0.1039 & 0.1126 & 0.2892 & 0.2448 & 0.1716 & 0.1046 & 0.0987 & 0.0480 & 0.1230 \\
\hline$s_{2}^{1}, s_{1}^{2}, s_{1}^{3}$ & 0.1257 & 0.1759 & 0.0649 & 0.1688 & 0.0783 & 0.1440 & 0.1011 & 0.1395 & 0.1875 & 0.1439 & 0.1901 \\
\hline$s_{3}^{1}, s_{1}^{2}, s_{1}^{3}$ & 0.1220 & 0.2435 & 0.0216 & 0.0950 & 0.2892 & 0.0768 & 0.0766 & 0.1201 & 0.1382 & 0.1259 & 0.1640 \\
\hline$s_{1}^{1}, s_{2}^{2}, s_{1}^{3}$ & 0.1960 & 0.1849 & 0.1039 & 0.1653 & 0.1627 & 0.1440 & 0.1287 & 0.1627 & 0.1349 & 0.0989 & 0.1864 \\
\hline$s_{2}^{1}, s_{2}^{2}, s_{1}^{3}$ & 0.0481 & 0.2255 & 0.0844 & 0.1759 & 0.1687 & 0.2592 & 0.1348 & 0.1356 & 0.1480 & 0.1259 & 0.1454 \\
\hline$s_{3}^{1}, s_{2}^{2}, s_{1}^{3}$ & 0.1960 & 0.1353 & 0.0476 & 0.0633 & 0.2651 & 0.1440 & 0.1869 & 0.1511 & 0.2204 & 0.1499 & 0.1230 \\
\hline$s_{1}^{1}, s_{3}^{2}, s_{1}^{3}$ & 0.2071 & 0.1984 & 0.0779 & 0.1970 & 0.0482 & 0.1872 & 0.1624 & 0.1240 & 0.1382 & 0.1049 & 0.0671 \\
\hline$s_{2}^{1}, s_{3}^{2}, s_{1}^{3}$ & 0.1627 & 0.2661 & 0.0411 & 0.1653 & 0.3555 & 0.1440 & 0.1532 & 0.1395 & 0.0789 & 0.0809 & 0.1901 \\
\hline$s_{3}^{1}, s_{3}^{2}, s_{1}^{3}$ & 0.1775 & 0.1623 & 0.0909 & 0.0985 & 0.2711 & 0.2304 & 0.1287 & 0.1627 & 0.1283 & 0.1349 & 0.1901 \\
\hline$s_{1}^{1}, s_{1}^{2}, s_{2}^{3}$ & 0.2071 & 0.1714 & 0.0952 & 0.1970 & 0.1446 & 0.1296 & 0.0674 & 0.1937 & 0.1678 & 0.1349 & 0.2088 \\
\hline$s_{2}^{1}, s_{1}^{2}, s_{2}^{3}$ & 0.1516 & 0.2300 & 0.1212 & 0.1337 & 0.2892 & 0.2160 & 0.1287 & 0.0581 & 0.0822 & 0.1259 & 0.1566 \\
\hline$s_{3}^{1}, s_{1}^{2}, s_{2}^{3}$ & 0.1553 & 0.1488 & 0.1039 & 0.1055 & 0.3374 & 0.1872 & 0.1103 & 0.0969 & 0.1579 & 0.1588 & 0.1342 \\
\hline$s_{1}^{1}, s_{2}^{2}, s_{2}^{3}$ & 0.1146 & 0.1668 & 0.0844 & 0.1970 & 0.2169 & 0.1968 & 0.1440 & 0.1860 & 0.2007 & 0.0989 & 0.1007 \\
\hline$s_{2}^{1}, s_{2}^{2}, s_{2}^{3}$ & 0.1368 & 0.1533 & 0.0736 & 0.1583 & 0.2470 & 0.1920 & 0.0735 & 0.0930 & 0.1250 & 0.1319 & 0.0708 \\
\hline$s_{3}^{1}, s_{2}^{2}, s_{2}^{3}$ & 0.2071 & 0.0361 & 0.0779 & 0.2005 & 0.1085 & 0.1776 & 0.0582 & 0.1356 & 0.0822 & 0.0899 & 0.1566 \\
\hline$s_{1}^{1}, s_{3}^{2}, s_{2}^{3}$ & 0.0813 & 0.2165 & 0.0844 & 0.1653 & 0.2049 & 0.1296 & 0.1287 & 0.1627 & 0.1842 & 0.0839 & 0.1678 \\
\hline$s_{2}^{1}, s_{3}^{2}, s_{2}^{3}$ & 0.1886 & 0.1984 & 0.0455 & 0.1653 & 0.3073 & 0.2016 & 0.1471 & 0.1976 & 0.1842 & 0.1169 & 0.1976 \\
\hline$s_{3}^{1}, s_{3}^{2}, s_{2}^{3}$ & 0.0703 & 0.2435 & 0.1017 & 0.0598 & 0.1868 & 0.2256 & 0.1624 & 0.0930 & 0.0329 & 0.1499 & 0.0708 \\
\hline
\end{tabular}

$$
\begin{array}{cc}
\operatorname{Max} v^{3} & \\
\text { subject to } & 0.3743 * \Phi_{1}^{3}+0.7051 * \Phi_{2}^{3} \geq v^{3} ; \\
& 0.5829 * \Phi_{1}^{3}+0.5862 * \Phi_{2}^{3} \geq v^{3} ; \\
& 0.4341 * \Phi_{1}^{3}+0.5986 * \Phi_{2}^{3} \geq v^{3} ; \\
& 0.6610 * \Phi_{1}^{3}+0.4228 * \Phi_{2}^{3} \geq v^{3} ;
\end{array}
$$

$$
\begin{aligned}
& 0.5549 * \Phi_{1}^{3}+0.4207 * \Phi_{2}^{3} \geq v^{3} ; \\
& 0.4895 * \Phi_{1}^{3}+0.6963 * \Phi_{2}^{3} \geq v^{3} ; \\
& 0.5482 * \Phi_{1}^{3}+0.5478 * \Phi_{2}^{3} \geq v^{3} ; \\
& 0.6444 * \Phi_{1}^{3}+0.4643 * \Phi_{2}^{3} \geq v^{3} ; \\
& 0.6160 * \Phi_{1}^{3}+0.3466 * \Phi_{2}^{3} \geq v^{3} ;
\end{aligned}
$$


TABLE 14: The aggregated performances in multiperson multicriteria noncooperation game of each enterprise.

\begin{tabular}{lcccr}
\hline \multirow{2}{*}{ Enterprise $P^{1}$} & Enterprise $P^{3}$ & \multicolumn{3}{c}{ Enterprise $P^{2}$} \\
& & $s_{1}^{2}$ & $s_{2}^{2}$ & $s_{3}^{2}$ \\
\hline \multirow{2}{*}{$s_{1}^{1}$} & $s_{1}^{3}$ & $(0.5254,0.7056,0.3743)$ & $(0.6501,0.4354,0.5829)$ & $(0.6804,0.3978,0.4341)$ \\
& $s_{2}^{3}$ & $(0.6706,0.3416,0.7051)$ & $(0.5629,0.5577,0.5862)$ & $(0.5475,0.4631,0.5986)$ \\
\hline \multirow{2}{*}{$s_{2}^{1}$} & $s_{1}^{3}$ & $(0.5354,0.3234,0.6610)$ & $(0.5338,0.5627,0.5549)$ & $(0.6352,0.6527,0.4895)$ \\
& $s_{2}^{3}$ & $(0.6365,0.6339,0.4228)$ & $(0.5220,0.5126,0.4207)$ & $(0.5978,0.6559,0.6963)$ \\
\multirow{2}{*}{$s_{3}^{1}$} & $s_{1}^{3}$ & $(0.4821,0.4426,0.5482)$ & $(0.4422,0.5960,0.6444)$ & $(0.5292,0.6302,0.6160)$ \\
& $s_{2}^{3}$ & $(0.5135,0.6349,0.5478)$ & $(0.5216,0.3443,0.4643)$ & $(0.4753,0.5748,0.3466)$ \\
\hline
\end{tabular}

Note: $(\bullet, \bullet, \bullet)$ represents the performance of each enterprise under different strategy combination $\left(P^{1}, P^{2}, P^{3}\right)$.

TABLE 15: The strategy combination occurrence probability distribution of each strategy of each enterprise.

\begin{tabular}{lcccc}
\hline Enterprise $P^{1}$ & Enterprise $P^{3}$ & \multicolumn{2}{c}{ Enterprise $P^{2}$} \\
& & $s_{1}^{2} \Phi_{1}^{2}=0.2136$ & $s_{2}^{2} \Phi_{2}^{2}=0.4629$ & $s_{3}^{2} \Phi_{2}^{2}=0.3235$ \\
\hline \multirow{2}{*}{$s_{1}^{1} \Phi_{1}^{1}=0.2632$} & $s_{1}^{3} \Phi_{1}^{3}=0.5956$ & 0.0335 & 0.0726 & 0.0507 \\
& $s_{2}^{3} \Phi_{2}^{3}=0.4044$ & 0.0227 & 0.0493 & 0.0344 \\
\multirow{2}{*}{$s_{2}^{1} \Phi_{2}^{1}=0.7368$} & $s_{1}^{3} \Phi_{1}^{3}=0.5956$ & 0.0937 & 0.2031 & 0.1420 \\
& $s_{2}^{3} \Phi_{2}^{3}=0.4044$ & 0.0636 & 0.1379 & 0.0964 \\
\multirow{2}{*}{$s_{3}^{1} \Phi_{3}^{1}=0.0000$} & $s_{1}^{3} \Phi_{1}^{3}=0.5956$ & 0.0000 & 0.0000 & 0.0000 \\
& $s_{2}^{3} \Phi_{1}^{3}=0.4044$ & 0.0000 & 0.0000 & 0.0000 \\
\hline
\end{tabular}

$$
\begin{aligned}
& \Phi_{1}^{3}+\Phi_{2}^{3}=1 ; \\
& \Phi_{1}^{3} \geq 0 \\
& \Phi_{2}^{3} \geq 0
\end{aligned}
$$

By solving this linear programming model, the optimal probability of strategies $s_{1}^{3}$ and $s_{2}^{3}$ is $\Phi_{1}^{3}=0.5956$ and $\Phi_{2}^{3}=$ 0.4044 , respectively.

Step 5. For the strategy combination, the occurrence probability distribution of each strategy of each enterprise can be calculated as Table 15. For example, the probability is 0.2031 for the strategy combination $\left(s_{2}^{1}, s_{2}^{2}, s_{1}^{3}\right)$ of enterprise $P^{1}, P^{2}$, and $P^{3}$. It means that the probability is 0.2031 when enterprise $P^{1}$ chooses strategy $s_{2}^{1}$, enterprise $P^{2}$ chooses strategy $s_{2}^{2}$, and enterprise $P^{3}$ chooses strategy $s_{1}^{3}$ simultaneously. Every enterprise can prepare to face the future competition scenario based on the occurrence probability distribution of each strategy of each enterprise.

4.3. The Meanings of Management. According to the execution probability of each strategy, the priority of enterprise $P^{1}$ is $s_{2}^{1}, s_{1}^{1}$, and $s_{3}^{1}$. The execution priority of enterprise $P^{2}$ is $s_{2}^{2}$, $s_{3}^{2}$, and $s_{1}^{2}$. The execution priority of enterprise $P^{3}$ is $s_{1}^{3}$ and $s_{2}^{3}$. The probability of each strategy combination is shown as Table 16. Each enterprise can prepare to handle the future possible competitive scenario based on the probability of each strategy combination. Therefore, the competition ability of enterprises can be compared based on the probability of each strategy combination.
TABLE 16: The probability of strategy combination.

\begin{tabular}{lc}
\hline Strategy combination & Probability \\
\hline$s_{2}^{1}, s_{2}^{2}, s_{1}^{3}$ & 0.2031 \\
$s_{2}^{1}, s_{3}^{2}, s_{1}^{3}$ & 0.1420 \\
$s_{2}^{1}, s_{2}^{2}, s_{2}^{3}$ & 0.1379 \\
$s_{2}^{1}, s_{3}^{2}, s_{2}^{3}$ & 0.0964 \\
$s_{2}^{1}, s_{1}^{2}, s_{1}^{3}$ & 0.0937 \\
$s_{1}^{1}, s_{2}^{2}, s_{1}^{3}$ & 0.0726 \\
$s_{2}^{1}, s_{1}^{2}, s_{2}^{3}$ & 0.0636 \\
$s_{1}^{1}, s_{3}^{2}, s_{1}^{3}$ & 0.0507 \\
$s_{1}^{1}, s_{2}^{2}, s_{2}^{3}$ & 0.0493 \\
$s_{1}^{1}, s_{3}^{2}, s_{2}^{3}$ & 0.0344 \\
$s_{1}^{1}, s_{1}^{2}, s_{1}^{3}$ & 0.0335 \\
$s_{1}^{1}, s_{1}^{2}, s_{2}^{3}$ & 0.0227 \\
Others & 0.0000 \\
\hline
\end{tabular}

The expected performance value (EPV) can be used to compare the competition ability of enterprises by considering the aggregated performance of each enterprise and the probability of each strategy combination. The higher expected performance value is, the higher enterprise competition ability is in the competitive environment.

According to Tables 14, 15, and 16, The EPV of enterprise $P^{1}$ can be computed as

$$
\begin{aligned}
& (0.5254 * 0.0335+0.6076 * 0.0227 \\
& +0.5354 * 0.0937+0.6365 * 0.0636 \\
& +0.4821 * 0.0000+0.5135 * 0.0000 \\
& +0.6501 * 0.0726+0.5629 * 0.0493
\end{aligned}
$$




$$
\begin{aligned}
& +0.5338 * 0.2031+0.5220 * 0.1379 \\
& +0.4422 * 0.0000+0.5216 * 0.0000 \\
& +0.6804 * 0.0507+0.5475 * 0.0344 \\
& +0.6352 * 0.1420+0.5978 * 0.0964 \\
& +0.5292 * 0.0000+0.4753 * 0.0000)=0.5800 .
\end{aligned}
$$

The EPV of enterprise $P^{2}$ can be computed as

$$
\begin{aligned}
& (0.7056 * 0.0335+0.3416 * 0.0227 \\
& +0.3234 * 0.0937+0.6339 * 0.0636 \\
& +0.4426 * 0.0000+0.6349 * 0.0000 \\
& +0.4354 * 0.0726+0.5577 * 0.0493 \\
& +0.5627 * 0.2031+0.5126 * 0.1379 \\
& +0.5960 * 0.0000+0.3443 * 0.0000 \\
& +0.3978 * 0.0507+0.4631 * 0.0344 \\
& +0.6527 * 0.1420+0.6559 * 0.0964 \\
& +0.6302 * 0.0000+0.5748 * 0.0000)=0.5381
\end{aligned}
$$

The EPV of enterprise $P^{3}$ can be computed as

$$
\begin{aligned}
& (0.3743 * 0.0335+0.7051 * 0.0227 \\
& +0.6610 * 0.0937+0.4228 * 0.0636 \\
& +0.5482 * 0.0000+0.5478 * 0.0000 \\
& +0.5829 * 0.0726+0.5862 * 0.0493 \\
& +0.5549 * 0.2031+0.4207 * 0.1379 \\
& +0.6444 * 0.0000+0.4643 * 0.0000 \\
& +0.4341 * 0.0507+0.5986 * 0.0344 \\
& +0.4895 * 0.1420+0.6963 * 0.0964 \\
& +0.6160 * 0.0000+0.3466 * 0.0000)=0.5386
\end{aligned}
$$

According to the EPV of each enterprise, the ranking order of competition ability is $P^{1}>P^{3}>P^{2}$.

\section{Conclusion and Future Research}

Facing the dynamic and competitive environment, a new decision making model is presented to deal with group MCDM problems by combining MCDM with game theory in this paper. Original game model usually considers one dimension to make decision based on crisp values. By using the linguistic variables, the decision makers can express their opinions flexibly and easily in the proposed method. According to the proposed method, each player in a game can develop the best strategy or alternative by considering the performance with respect to multiple criteria and the reactions of competitors simultaneously. A particular strongpoint of this proposed method is that the evaluation criteria can be flexible to determine by players for fitting their objections. Under this situation, the proposed method provides a more reasonable and systematic solution for each player in a competitive environment.

In fact, the number of players of a game model can increase more than two players flexibly in the proposed method. In addition, the most important contribution of proposed method is to present the expected performance value (EPV) to judge the competitive ability of each player in a game model. In the future, multiple types of decision information will be considered in the proposed model such as interval value, crisp value, and type- 2 fuzzy set. In order to enhance the computational efficiency, an interactive program will be designed based on the proposed model.

\section{Conflict of Interests}

The authors declare that there is no conflict of interests regarding the publication of this paper.

\section{Acknowledgment}

This work is financially supported partially by the National Science Council of Taiwan, Grant no. NSC 101-2410-H-239004-MY2.

\section{References}

[1] J. von Neumann and D. Morgenstern, The Theory of Games and Economics Behavior, John Wiley \& Sons, New York, NY, USA, 1944.

[2] F. Bellotti, R. Berta, A. de Gloria et al., "Designing a course for stimulating entrepreneurship in higher education through serious games," Procedia Computer Science, vol. 15, pp. 174-186, 2012.

[3] D. Berga, G. Bergantiños, J. Massó, and A. Neme, "An undominated Nash equilibrium for voting by committees with exit," Mathematical Social Sciences, vol. 54, no. 2, pp. 152-175, 2007.

[4] M. R. Hoogeweegen, D. W. van Liere, P. H. M. Vervest, L. H. van der Meijden, and I. de Lepper, "Strategizing for mass customization by playing the business networking game," Decision Support Systems, vol. 42, no. 3, pp. 1402-1412, 2006.

[5] G. Moschini, "Nash equilibrium in strictly competitive games: live play in soccer," Economics Letters, vol. 85, no. 3, pp. 365-371, 2004.

[6] Q. Song and A. Kandel, "A fuzzy approach to strategic games," IEEE Transactions on Fuzzy Systems, vol. 7, no. 6, pp. 634-642, 1999.

[7] L. Campos, "Fuzzy linear programming models to solve fuzzy matrix games," Fuzzy Sets and Systems, vol. 32, no. 3, pp. 275289, 1989.

[8] M. Sakawa and I. Nishizaki, "Max-min solutions for fuzzy multiobjective matrix games," Fuzzy Sets and Systems, vol. 67, no. 1, pp. 53-69, 1994.

[9] J. H. Wang, A fuzzy approach on N-person multi attribute noncooperative game [M.S. thesis], I-Shou University, 2004. 
[10] P. Y. Liao, Analyzing the wireless LAN market: an approach of two person zero sum game with multiple fuzzy goals [M.S. thesis], National Chiao Tung University, 2006.

[11] G. N. Angelou and A. A. Economides, "A multi-criteria game theory and real-options model for irreversible ICT investment decisions," Telecommunications Policy, vol. 33, no. 10-11, pp. 686-705, 2009.

[12] J. A. Reneke, "A game theory formulation of decision making under conditions of uncertainty and risk," Nonlinear Analysis: Theory, Methods and Applications, vol. 71, no. 12, pp. el239e1246, 2009.

[13] K. Madani and J. R. Lund, "A Monte-Carlo game theoretic approach for Multi-Criteria Decision Making under uncertainty," Advances in Water Resources, vol. 34, no. 5, pp. 607-616, 2011.

[14] L. Monroy and F. R. Fernández, "The Shapley-Shubik index for multi-criteria simple games," European Journal of Operational Research, vol. 209, no. 2, pp. 122-128, 2011.

[15] A. S. Barough, M. V. Shoubi, and M. J. E. Skardi, "Application of game theory approach in solving the construction project conflicts," Procedia-Social and Behavioral Sciences, vol. 58, pp. 1586-1593, 2012.

[16] D.-F. Li and F.-X. Hong, "Solving constrained matrix games with payoffs of triangular fuzzy numbers," Computers and Mathematics with Applications, vol. 64, pp. 432-446, 2011.

[17] L. Monroy and F. R. Fernández, "Stable sets and cores for multicriteria simple games and for their extensions," Social Choice and Welfare, vol. 39, no. 1, pp. 1-22, 2011.

[18] V. Lozan and V. Ungureanu, "The set of pareto-nash equilibria in multicriteria strategic games," Computer Science, vol. 20, no. 1, pp. 58-70, 2012.

[19] L. Pusillo and S. Stef Tijs, "E-equilibria for multicriteria games," in Advances in Dynamic Games, pp. 217-228, Birkhäauser, Boston, Mass, USA, 2013.

[20] T. Kawamura, T. Kanazawa, and T. Ushio, "Evolutionarily and neutrally stable strategies in multicriteria games," IEICE Transactions on Fundamentals of Electronics, Communications and Computer Sciences, vol. 96, no. 4, pp. 814-820, 2013.

[21] S. K. Roy and C. B. Das, "Multicriteria entropy bimatrix goal game: a fuzzy programming approach," Journal of Uncertain Systems, vol. 7, no. 2, pp. 108-117, 2013.

[22] L. A. Zadeh, "Fuzzy sets," Information and Control, vol. 8, no. 3, pp. 338-353, 1965.

[23] Z. Xu, "Group decision making based on multiple types of linguistic preference relations," Information Sciences, vol. 178, no. 2, pp. 452-467, 2008.

[24] R. R. Yager, "An approach to ordinal decision making," International Journal of Approximate Reasoning, vol. 12, no. 3-4, pp. 237-261, 1995.

[25] C.-T. Lin and Y.-T. Chen, "Bid/no-bid decision-making: a fuzzy linguistic approach," International Journal of Project Management, vol. 22, no. 7, pp. 585-593, 2004.

[26] R.-C. Wang and S.-J. Chuu, "Group decision-making using a fuzzy linguistic approach for evaluating the flexibility in a manufacturing system," European Journal of Operational Research, vol. 154, no. 3, pp. 563-572, 2004.

[27] W.-P. Wang, "A fuzzy linguistic computing approach to supplier evaluation," Applied Mathematical Modelling, vol. 34, no. 10, pp. 3130-3141, 2010.

[28] C.-T. Chen, "Extensions of the TOPSIS for group decisionmaking under fuzzy environment," Fuzzy Sets and Systems, vol. 114, no. 1, pp. 1-9, 2000.
[29] C.-T. Chen and W.-Z. Hung, "A new decision-making method for stock portfolio selection based on computing with linguistic assessment," Journal of Applied Mathematics and Decision Sciences, vol. 2009, Article ID 897024, 20 pages, 2009.

[30] E. Herrera-Viedma and E. Peis, "Evaluating the informative quality of documents in SGML format from judgements by means of fuzzy linguistic techniques based on computing with words," Information Processing and Management, vol. 39, no. 2, pp. 233-249, 2003.

[31] J. Pang and J. Liang, "Evaluation of the results of multi-attribute group decision-making with linguistic information," Omega, vol. 40, no. 3, pp. 294-301, 2012.

[32] L. A. Zadeh, "The concept of a linguistic variable and its application to approximate reasoning-II," Information Sciences, vol. 8, no. 4, pp. 301-357, 1975.

[33] C. T. Chen, P. F. Pai, and W. Z. Hung, "A two-phase fuzzy decision-making method based on multigranular linguistic assessment," African Journal of Business Management, pp. 71987213, 2012.

[34] A. Kaufmann and M. M. Gupta, Introduction to Fuzzy Arithmetic: Theory and Applications, International Thomson Computer Press, London, UK, 1991.

[35] E. S. Lee and R.-J. Li, "Comparison of fuzzy numbers based on the probability measure of fuzzy events," Computers and Mathematics with Applications, vol. 15, no. 10, pp. 887-896, 1988.

[36] M. Bevilacqua, F. E. Ciarapica, and G. Giacchetta, "A fuzzyQFD approach to supplier selection," Journal of Purchasing and Supply Management, vol. 12, no. 1, pp. 14-27, 2006.

[37] L.-S. Chen and C.-H. Cheng, "Selecting IS personnel use fuzzy GDSS based on metric distance method," European Journal of Operational Research, vol. 160, no. 3, pp. 803-820, 2005.

[38] C.-H. Cheng and Y. Lin, "Evaluating the best main battle tank using fuzzy decision theory with linguistic criteria evaluation," European Journal of Operational Research, vol. 142, no. 1, pp. 174-186, 2002.

[39] M. Modarres and S. Sadi-Nezhad, "Ranking fuzzy numbers by preference ratio," Fuzzy Sets and Systems, vol. 118, no. 3, pp. 429436, 2001. 


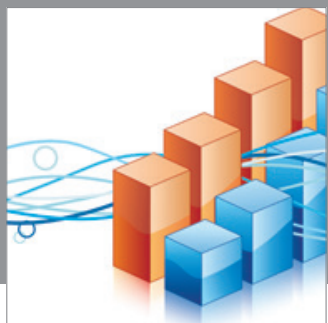

Advances in

Operations Research

mansans

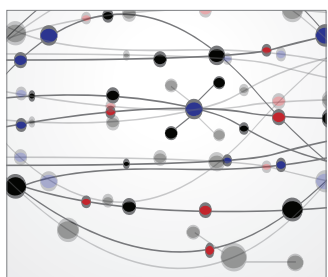

The Scientific World Journal
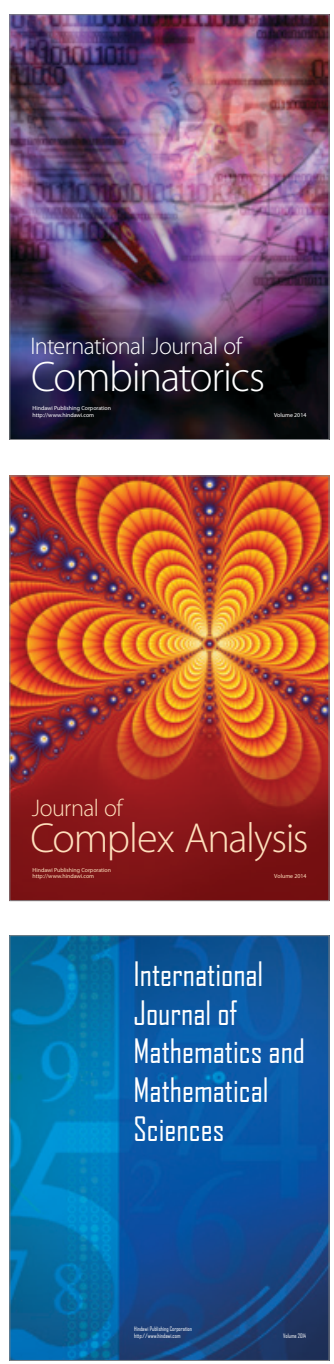
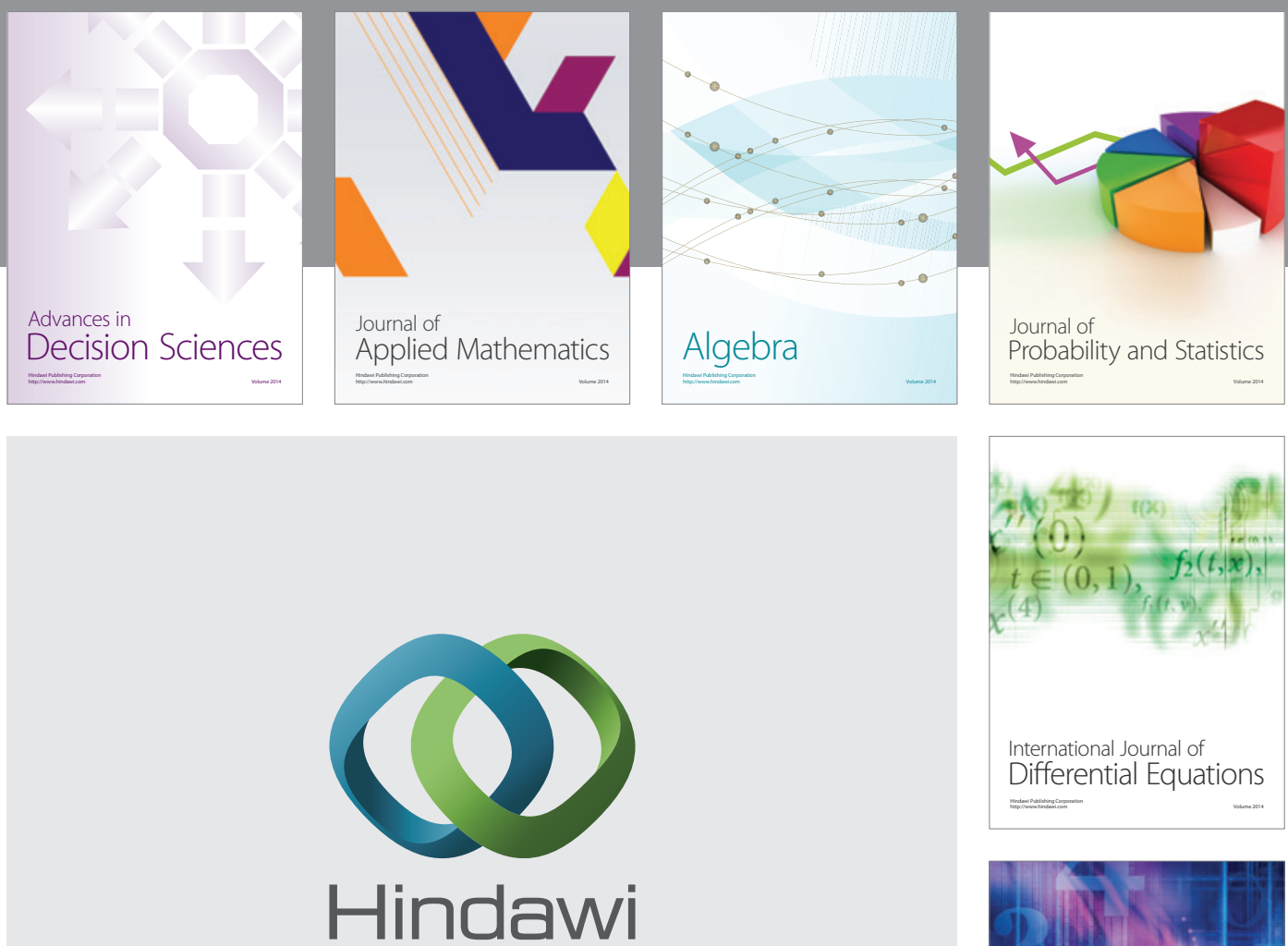

Submit your manuscripts at http://www.hindawi.com
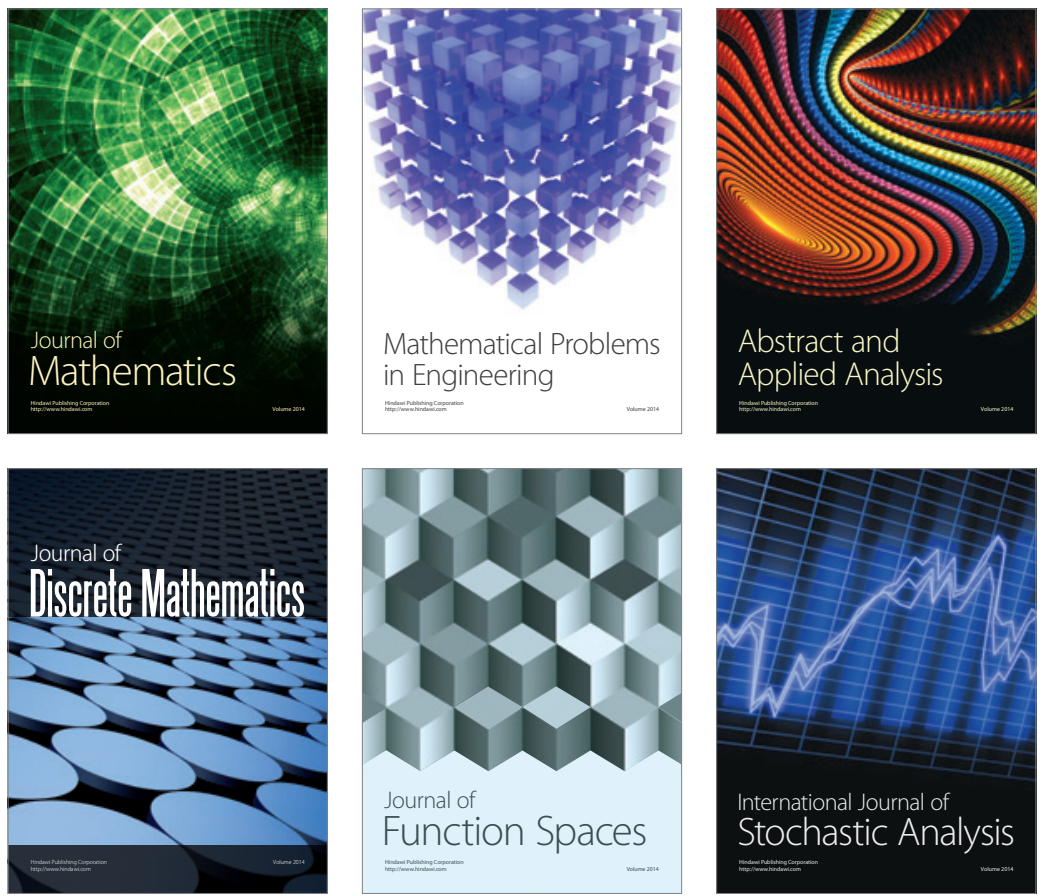

Journal of

Function Spaces

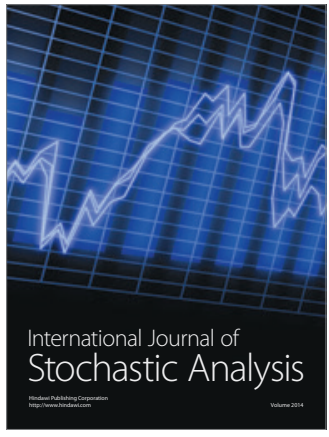

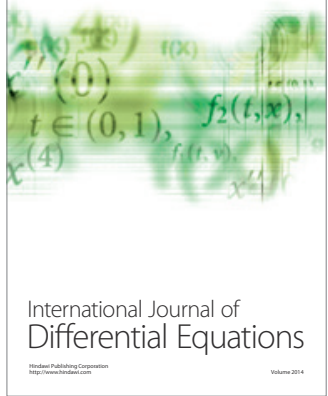
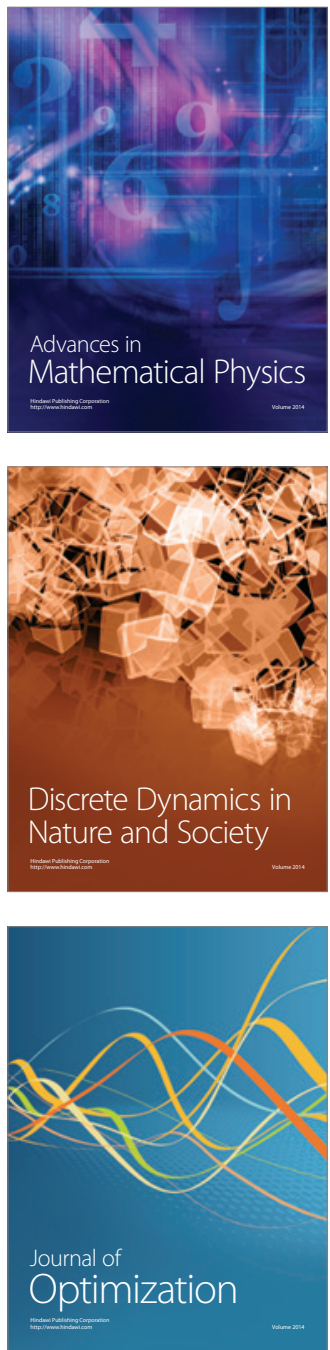